\title{
Bacterial Toxins as Pathogen Weapons Against Phagocytes
}

\author{
Ana do Vale ${ }^{1,2 *}$, Didier Cabanes ${ }^{1,3}$ and Sandra Sousa ${ }^{1,3 *}$ \\ ${ }^{1}$ Host Interaction and Response, Instituto de Investigação e Inovação em Saúde, Universidade do Porto, Porto, Portugal, \\ ${ }^{2}$ Group of Fish Immunology and Vaccinology, Instituto de Biologia Molecular e Celular, Universidade do Porto, Porto, \\ Portugal, ${ }^{3}$ Group of Molecular Microbiology, Instituto de Biologia Molecular e Celular, Universidade do Porto, Porto, Portugal
}

Bacterial toxins are virulence factors that manipulate host cell functions and take over the control of vital processes of living organisms to favor microbial infection. Some toxins directly target innate immune cells, thereby annihilating a major branch of the host immune response. In this review we will focus on bacterial toxins that act from the extracellular milieu and hinder the function of macrophages and neutrophils. In particular, we will concentrate on toxins from Gram-positive and Gram-negative bacteria that manipulate cell signaling or induce cell death by either imposing direct damage to the host cells cytoplasmic membrane or enzymatically modifying key eukaryotic targets. Outcomes regarding pathogen dissemination, host damage and disease progression will be discussed.

Keywords: bacterial exotoxin, macrophage, neutrophil, phagocyte, immunomodulation, innate immune response

\section{INTRODUCTION}

Macrophages and neutrophils are central mediators of the innate immune system that act at early stages of bacterial infection and have the ability to clear the pathogen through phagocytosis and subsequent digestion (Mantovani et al., 2011; Wynn et al., 2013). Besides their overlapping functional properties, macrophages, and neutrophils also display distinct and specialized features allowing their concerted and cooperative action against pathogens (Appelberg, 2007; Silva, 2010; Silva and Correia-Neves, 2012). Accordingly to their antimicrobial capacity, toxicity, and lifespan, macrophages and neutrophils have different localizations. Long-lived macrophages are distributed in tissues throughout the body where they perform local immune surveillance activities, including recognition, phagocytosis, and rapid signaling of invading pathogens. The number of resident macrophages in resting tissues is rather low. Upon infection resident macrophages secrete chemokines, rapidly recruiting monocytes, and quiescent neutrophils from blood and bone marrow pools to the infectious foci. Monocytes differentiate to short-lived mature macrophages and neutrophils are activated to produce powerful antimicrobial molecules and release proinflammatory cytokines and chemokines amplifying the initial chemotactic role of resident macrophages and sustaining antimicrobial activities (Mantovani et al., 2011; Wynn et al., 2013).

The outcome of an infection is dictated by the nature of host-pathogen interactions and greatly depends on the efficacy of phagocytes. When, through the action of virulence determinants, the pathogen takes the control of the interaction in detriment of the host, the infection establishes. By the contrary, if the host immune defenses dominate over the pathogen, the infection is controlled and the pathogen is eliminated. In this scenario, several human pathogens evolved an arsenal of sophisticated mechanisms to evade host defenses. In particular, given the central role of macrophages and neutrophils as primary phagocytes, 
several pathogens deploy strategies to either survive or annihilate phagocytes antimicrobial functions (Flannagan et al., 2009). To avoid macrophage antimicrobial properties, some intracellular pathogens interfere with the classical maturation of the phagosome, blocking fusion with endosomes, and lysosomes thereby preventing destruction. Others escape the phagosome to multiply in the cytosol and modulate host gene expression to limit production of cytokines that would be deleterious for pathogen progression. Despite the mechanisms of evasion of neutrophil-killing are yet poorly defined, it is known that some pathogens survive and multiply inside neutrophils which may act as Trojan horses for microbial dissemination (Appelberg, 2007). From the extracellular milieu, some pathogens target macrophage and neutrophils mainly through the secretion of toxins that: (1) cause irreversible damage leading to phagocyte death or (2) heavily perturb intracellular signaling pathways, blocking phagocytosis or modulating inflammation (e.g., through the control of expression of chemokines and cytokines; Lemichez and Barbieri, 2013).

Toxins are potent molecules produced by a large variety of bacterial pathogens that target host cells and play key roles in the host-pathogen dialog. They are major virulence factors often sufficient to determine the outcome of the infection. Indeed, attesting their importance in pathogenesis, the injection of small amounts of some purified toxins can recapitulate many key symptoms of the disease. Bacterial toxins can be divided in several groups regarding their nature and mode of action (Lemichez and Barbieri, 2013). In this review we focus on bacterial exotoxins, which are secreted by the pathogen and act on the host cells from the extracellular milieu. Although exotoxins may target different cell types, some specifically target macrophages and neutrophils thus taking the control of innate immune response, providing the pathogen a suitable environment for active proliferation. Interestingly, while the initial steps of phagocytes intoxication are specific for different exotoxins, the ultimate cellular effects leading to the loss of host cell function are often the same. Taking this into account we review here the mechanisms of phagocyte targeting by archetypal exotoxins such as pertussis toxin (PT) and adenylate cyclase toxin (ACT) secreted by Bordetella pertussis, anthrax toxin from Bacillus anthracis and Staphylococcus aureus leukotoxins. We also include here AIP56, a recently described toxin from Photobacterium damselae piscicida (Phdp). In addition, the mode of action of mycolactone, a polyketide molecule produced by Mycobacterium ulcerans, and other bacterial secreted products not formally termed as toxins, such as $S$. aureus superantigens-like proteins (SSLs) and phenolsoluble modulins (PSMs), are also reviewed here. Clostridial C3 toxins, which target and modulate macrophage functions, are the focus of another review in this Topic (Barth et al., 2015).

\section{Bordetella pertussis: TWO TOXINS ARE BETTER THAN ONE}

Bordetella pertussis is a Gram-negative pathogen that infects the human respiratory tract causing whooping cough, an acute and highly contagious infection (Mattoo and Cherry, 2005; Melvin et al., 2014). Initially thought to be a toxin-mediated disease (Pittman, 1984), such as cholera and diphtheria, pertussis disease is instead the result of the coordinated action of a variety of bacterial factors that allow bacterial adherence to ciliated respiratory epithelium, survival to host innate immune defense, multiplication, and resistance to inflammatory cells (Carbonetti, 2007). Two of the major virulence factors of $B$. pertussis are the secreted toxins, PT and ACT, which emerged as key elements for suppression/modulation of the host immune and inflammatory responses (Carbonetti, 2010; Higgs et al., 2012; Melvin et al., 2014). Interestingly, mouse infections with different mutants suggested that these two toxins have complementary functions in pathogenesis assaulting the innate immune cells at different times and from different angles. PT would act at early stages of infection mainly inhibiting the recruitment of immune cells, while ACT would later intoxicate macrophages and neutrophils blocking bacterial engulfment and destruction (Carbonetti et al., 2005).

\section{First Round: PT Inflicts First Blow to the Host}

Pertussis toxin is a multisubunit AB-toxin exclusively produced by $B$. pertussis. Through B-subunits, PT binds to any sialic acid-containing glycoprotein at the cellular surface (Witvliet et al., 1989; Saukkonen et al., 1992; Stein et al., 1994), is internalized by endocytosis and follows a retrograde transport pathway through the Golgi complex to the endoplasmic reticulum (Plaut and Carbonetti, 2008; Figure 1), from which the A-subunit translocate to the cytoplasm of host cells (Locht et al., 2011). In the host cell cytosol, the A-subunit exhibits ADP-ribosyltransferase activity, hydrolysing NAD and ADPribosylating heteromeric G-proteins of the $\mathrm{G}_{\mathrm{i}}$ family (Katada et al., 1983). This modification prevents the interaction of $G_{i}$ proteins with their cognate G-protein coupled receptors (GPCRs) causing the disruption of downstream cell signaling transduction (Mangmool and Kurose, 2011). Besides the activity of the A domain, B-subunits also display signaling function by activating intracellular signaling cascades in a $G_{i}$-protein independent manner (Mangmool and Kurose, 2011).

Pertussis toxin has long been considered as a major B. pertussis virulence factor. Indeed, PT was reported to be the cause of systemic symptoms of pertussis disease such as lymphocytosis and leukocytosis (Morse and Morse, 1976) and was associated with lethal infection by $B$. pertussis in a neonatal mouse model (Goodwin and Weiss, 1990). However, evidences supporting its role in respiratory infection have only emerged in the last decade. Experiments in the mouse model revealed that the lack of PT confers a defect in B. pertussis colonization at the early stages of infection (Carbonetti et al., 2003, 2005). Interestingly, a PT-deficient strain reaches wild type levels of colonization whenever co-infections with both strains are performed or intranasal inoculation of purified PT precedes infection (Carbonetti et al., 2003). Further studies have shown that depletion of resident airway macrophages leads to exacerbated $B$. pertussis infection in a PT-independent manner (Carbonetti et al., 2007), indicating that PT targets 


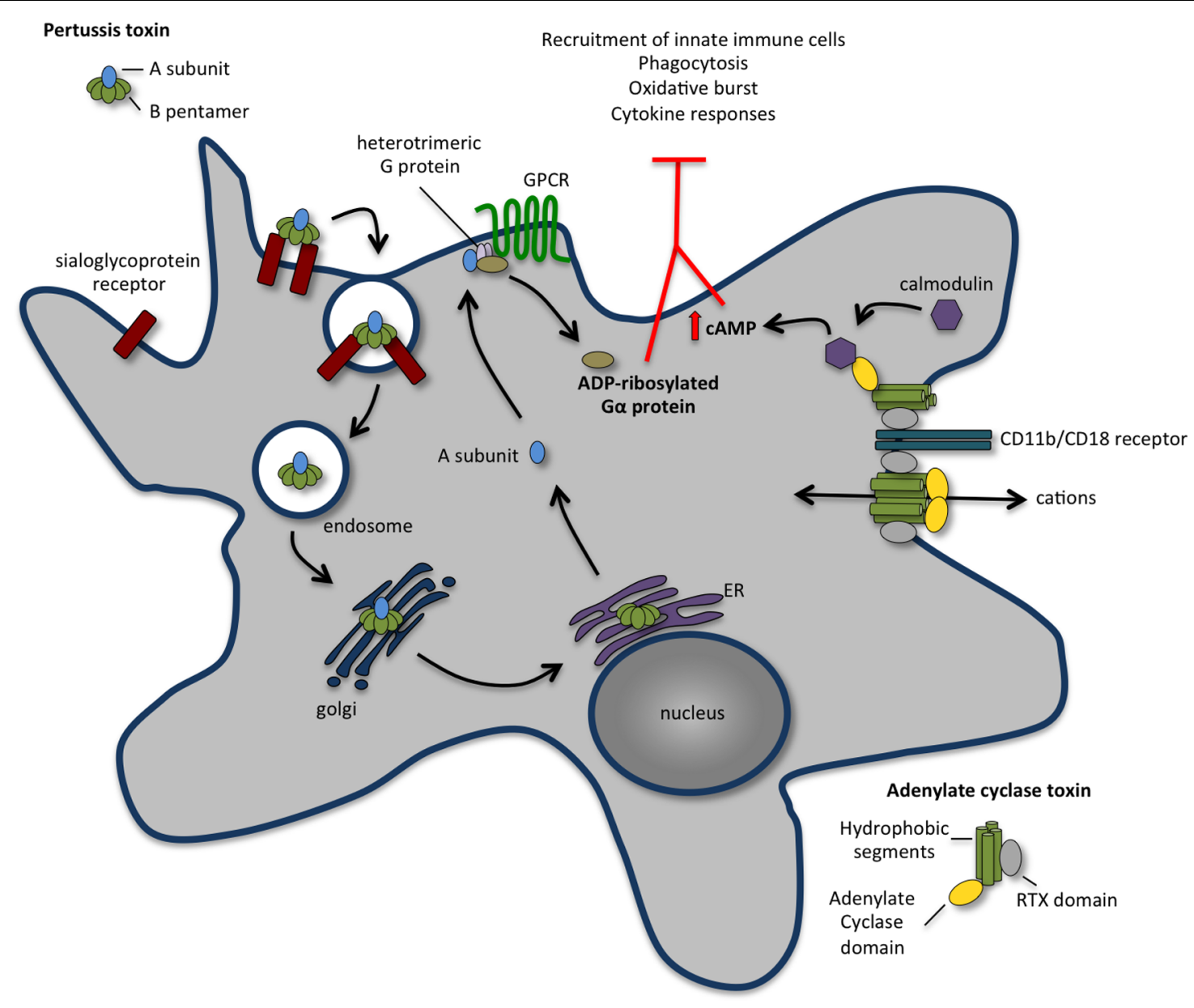

FIGURE 1 | The concerted action of pertussis toxin (PT) and adenylate cyclase toxin (ACT) annihilates recruitment and function of innate immune cells. Following binding to a sialoglyprotein receptor, PT is endocytosed and retrogradely transported to the endoplasmic reticulum (ER). From the ER, the A subunit is delivered into the cytosol and travels to the plasma membrane, where it ADP-ribosylates the alpha-subunit of heterotrimeric G proteins, perturbing their regulatory functions and leading to an increase in the cAMP concentration that contributes to the early suppression of inflammatory cytokine production and inhibits the recruitment of immune cells to the site of infection. ACT binds with high affinity to CD11b/CD18 receptor [also known as complement receptor 3 (CR3) or macrophage-1 antigen (Mac-1)] present at the surface of macrophages, neutrophils, and dendritic cells. Upon binding, ACT integrates the membrane of target cell in two different conformations: a translocation precursor that relocalises at lipid raft domains from where the adenylate cyclase activity translocates directly to the cell cytoplasm; and a pore precursor that oligomerises and permeabilises the cells causing ion concentration imbalance. Binding of calmodulin stimulates the adenylate cyclase, leading to an increase in intracellular levels of cAMP. The activity of ACT inhibits complement-mediated phagocytosis, inhibits the production of pro-inflammatory cytokines and interferes with immune cell recruitment.

airway macrophages disrupting their protective activity at early steps of infection (Carbonetti et al., 2007). Intranasal administration of PT resulted in ADP-ribosylation of airway macrophages $G_{i}$-proteins (Carbonetti et al., 2007), suggesting that its inhibitory function on macrophages in vivo results from the immunosuppressive activities ascribed to $\mathrm{PT}$ in vitro. In particular, in vitro PT was shown to inhibit macrophage and neutrophil migration (Meade et al., 1984), phagocytosis (Mork and Hancock, 1993) and cytokine response (He et al., 1988; Hume and Denkins, 1989).

In vivo, PT plays a dual role in the establishment of the disease. Whereas it has immunosuppressive functions at early stages of infection, later it potentiates inflammatory responses, likely prolonging healing and promoting bacterial dissemination
(Eby et al., 2015). Early in infection, PT targets airway macrophages and inhibits neutrophil recruitment to the infection site (Carbonetti et al., 2003, 2005; Kirimanjeswara et al., 2005; Andreasen and Carbonetti, 2008). Neutrophils were reported to play a protective role against $B$. pertussis only in previously infected mice and in the presence of anti- $B$. pertussis antibodies (Kirimanjeswara et al., 2005; Andreasen and Carbonetti, 2009), which may suggest that PT delays neutrophil recruitment to the airways avoiding rapid antibody-mediated clearance of the pathogen. Later, at the peak of infection, high numbers of neutrophils are recruited to the lungs of mice infected with wild type strain, but not to those infected with PT-deficient strain (Carbonetti et al., 2005; Andreasen et al., 2009). This recruitment of neutrophils to the lungs correlates with an increase of 
proinflammatory cytokines such as IL-17, TNF $\alpha$ and IFN $\gamma$ that appears to be dependent on PT activity (Andreasen et al., 2009). Recently, global transcriptional profiles of mice lungs infected with wild type or PT-deficient $B$. pertussis revealed that, at the peak of infection, the ADP-ribosylation activity of PT correlates with upregulation of immune and inflammatory response genes (Connelly et al., 2012). In vitro studies suggested that PT directly impairs neutrophil migration through ADP-ribosylation the $\mathrm{G}_{\mathrm{i}^{-}}$ proteins associated with surface chemokine receptors (Spangrude et al., 1985; Scott et al., 1988; Figure 1). However, in vivo data showed that besides acting directly on chemokine receptors signaling (Kirimanjeswara et al., 2005), PT also suppresses early neutrophil recruitment by inhibiting the production of neutrophil-attracting chemokines by airway macrophages and lung epithelial cells (Andreasen and Carbonetti, 2008). Transcription of genes expressing CXCL1, CXCL2, and CXCL5 is inhibited in the lungs of mice intranasally infected with wild type $B$. pertussis, as compared to animals infected with strains deficient for PT production or producing a PT variant devoid of ADP-ribosylation activity (Andreasen and Carbonetti, 2008). Interestingly, PT also blocks chemokine gene expression and early neutrophil recruitment to the airways following intranasal administration of LPS (Andreasen and Carbonetti, 2008), which occurs presumably through modulation of TLR-4 signaling, a $\mathrm{G}_{\mathrm{i}}$-protein independent pathway.

Altogether, these studies show that PT suppresses early inflammation in the respiratory tract and inhibit microbicidal function of inflammatory cells, potentially providing advantage to the pathogen by allowing its rapid growth and establishment within the host at early phases of infection.

\section{Second Round: ACT Perpetuates the Pathogen Gain}

Adenylate cyclase toxin is a bi-functional toxin produced by all species of Bordetella that infect mammals. While its $\mathrm{N}$-terminal domain contains an adenylate cyclase activity that converts ATP in cAMP, the C-terminus possesses RTX motifs that bind mammalian cells and form cation-selective pores in the host plasma membrane. Through its combined adenylate cyclase and pore-forming activities, ACT manipulates host cell physiology in two different ways: it interferes with intracellular signaling by increasing the levels of cAMP, and disturbs ion homeostasis by disrupting the permeability barrier of the plasma membrane (Figure 1). ACT specifically binds with high affinity CD11b/CD18 (also known as CR3 or Mac-1) present at the surface of macrophages, neutrophils and dendritic cells (DCs; Guermonprez et al., 2001). Upon binding, ACT integrates the membrane of target cells in two different conformations: a translocation precursor that re-localizes at lipid raft domains from where the adenylate cyclase activity translocates directly to the cell cytoplasm; and a pore precursor that oligomerises and permeabilises the cells causing ion concentration imbalance (Fiser et al., 2007, 2012; Bumba et al., 2010; Figure 1). While the rapid translocation of adenylate cyclase activity across the host plasma membrane does not dependent on endocytosis (Gordon et al., 1988), the clathrin-dependent endocytosis of ACT together with its receptor CD11b/CD18 was reported (Khelef et al., 2001; Martin et al., 2011). Classical mechanisms of membrane repair upon toxin-induced pore formation include the removal of the pores through endocytosis. Interestingly, ACT-translocated molecules control the rate of ACT-pore removal delaying their endocytic uptake, thus exacerbating the permeabilisation of phagocytes and maximizing the cytotoxic action (Fiser et al., 2012). Despite its interaction with a specific receptor, ACT was reported to promiscuously bind and intoxicate many cell types, including CD11b/CD18-negative cells (Ladant and Ullmann, 1999; Paccani et al., 2008; Eby et al., 2012), although the biological relevance of these findings remains unclear. Indeed, while ACT triggers macrophage apoptosis in vitro (Khelef et al., 1993; Khelef and Guiso, 1995) and in vivo (Gueirard et al., 1998), the viability of cells from non-haematopietic origin remains unaffected (Gueirard et al., 1998; Bassinet et al., 2000). In vivo studies support that ACT primarily targets phagocytes such as alveolar macrophages and neutrophils, disrupting the early innate antibacterial host immune response (Harvill et al., 1999; Figure 1).

cAMP is a key second messenger with pleiotropic effects. Increased levels of cAMP severely compromise cellular functions such as the migration of neutrophils, the plasticity of DC responses, the release of cytokines by macrophages and the homeostasis of actin cytoskeleton. Thus, through the uncontrolled production of intracellular cAMP, ACT subverts phagocytic, and bactericidal function of macrophages and neutrophils in a variety of ways (Figure 1). In human alveolar macrophages and neutrophils, as in mouse macrophages, the ACT-mediated cAMP production blocks phagocytosis, chemotaxis, and oxidative burst (Confer and Eaton, 1982; Friedman et al., 1987; Weingart and Weiss, 2000; Kamanova et al., 2008; Eby et al., 2014). High levels of cAMP cause a transient inactivation of RhoA inducing massive actin rearrangements that dramatically decrease macropinocytosis, block complementmediated phagocytosis (Kamanova et al., 2008) and possibly impair the chemotactic properties of primary monocytes. Recently, ACT-induced cAMP synthesis was shown to trigger pro-apoptotic signaling in phagocytes through the activity of tyrosine phosphatase SHP-1, the accumulation of cytosolic BimEL and the consequent activation of Bax, permeabilisation of the outer mitochondrial membrane and activation of programmed cell death (Ahmad et al., 2015; Cerny et al., 2015). Besides the immediate action of ACT on the ablation of bactericidal functions of phagocytes, ACT activity was also reported to block the release of $\mathrm{TNF} \alpha$ and the production of ROS in human monocytes (Njamkepo et al., 2000), to promote incomplete or aberrant maturation of DCs (Skinner et al., 2004; Boyd et al., 2005) and to impair T-cell activation by interfering with immunological synapse signaling (Paccani et al., 2011). ACT was described to suppress the secretion of pro-inflammatory cytokines such as IL-12 and TNF $\alpha$ and favor the production of anti-inflammatory IL-10 molecules (Spensieri et al., 2006; Hickey et al., 2008).

Despite the fact that studies in mouse models established ACT as an important virulence factor for B. pertussis infection (Khelef et al., 1992), the effects described above were obtained from 
in vitro studies, and their significance during in vivo infection requires further investigation. Importantly, recent studies using baboon infection model and clinical samples from humans showed that the concentration of ACT in tissues is much lower than the amount used for in vitro experiments (Eby et al., 2013), which may compromise the relevance of some effects reported in vitro.

Pertussis toxin and ACT have undeniable roles during $B$. pertussis infection and certainly play key functions in the pathophysiology of pertussis disease. Numerous and wideranging effects of the purified toxins on cultured cell lines have been reported, however, establishing the correlation of such effects with the human pathology appeared as an incredible difficult task. In addition, the mouse model only provides limited possibilities to address this issue. Together with analysis of clinical samples from humans, the use of baboons as non-human primate model is expected to shed new light on the mechanisms of action of PT and ACT and on pertussis disease.

\section{Bacillus anthracis: ARMED TO ANNIHILATE THE HOST INNATE IMMUNE DEFENSES}

Bacillus anthracis is a Gram-positive, spore-forming rod that causes anthrax, an acute and fast progressing disease that affects humans and other animals, and results from a combination of bacterial infection and toxemia (Moayeri et al., 2015). The spores, which are the infectious form of the pathogen, are able to resist harsh environmental conditions and to infect new hosts when inhaled, ingested, or exposed to skin breaks. Upon entering a potential host, spores germinate into vegetative bacilli that replicate and disseminate through the bloodstream, leading to a systemic infection. Whereas in experimental inhalational anthrax, spore germination requires engulfment by macrophages/DCs (Guidi-Rontani et al., 1999; Hanna and Ireland, 1999), in experimental cutaneous infections it has been shown that most of the spore germination occurs extracellularly (Bischof et al., 2007; Corre et al., 2013). Soon after spore germination, vegetative $B$. anthracis start producing two potent exotoxins - anthrax lethal toxin (LT) and edema toxin (ET) that along with a poly-D-glutamic acid capsule, are its major virulence factors (Moayeri et al., 2015). B. anthracis also secretes anthrolysin $\mathrm{O}$ (ALO), a member of the cholesterol-dependent cytolysin family (Shannon et al., 2003). ALO is cytotoxic for several mono- and polymorphonuclear cells (Shannon et al., 2003; Cocklin et al., 2006; Mosser and Rest, 2006) and together with LT, induces apoptosis of macrophages (Shannon et al., 2003). However, ALO-deficient and wild-type strains revealed no differences in virulence in an inhalation infection model (Heffernan et al., 2007). Consistent with these observations, ALO-based vaccines, although conferring protection against lethal intravenous challenge with ALO, do not protect mice against peritoneal infection by B. anthracis (Cowan et al., 2007). Altogether, available data indicate that ALO is not essential for $B$. anthracis virulence and thus further studies are needed to determine if ALO contributes to B. anthracis pathogenicity.
Anthrax toxins originate from the association of three different protein components: a host cell receptor binding protein named protective antigen (PA) and two enzymatic proteins, edema factor (EF) and lethal factor (LF) (Young and Collier, 2007; Figure 2). EF or LF associated to PA is referred as ET or LT, respectively. Host cell intoxication begins when PA binds to either tumor endothelium marker 8 (TEM8, also known as anthrax toxin receptor 1, ANTXR1) or capillary morphogenesis protein 2 (CMG2, also known as anthrax toxin receptor 2, ANTXR2), which are expressed by different cell types, including macrophages and neutrophils (Bradley et al., 2001; Scobie et al., 2003). Although both TEM8 and CMG2 can function as anthrax toxin receptors, studies with TEM8- and CMG2-null mice have shown that CMG2 is the major anthrax toxin receptor mediating toxin lethality in vivo and that TEM8 plays only a minor role in anthrax toxin-associated pathogenesis (Liu et al., 2009). Upon binding to its cell surface receptor, PA is proteolytically processed at its N-terminus by a furin-like protease and self-assembles forming an oligomeric prepore able to bind EF and LF. The EF and/or LF-prepore-receptor complex undergoes receptor-mediated endocytosis (Abrami et al., 2003) and the acidic conditions in endosomes induce conversion of the prepore to a pore, allowing translocation of EF and LF into the cell cytosol (Collier, 2009) to exert their cytotoxic effects (Figure 2). In endosomes, the toxin complex can also be sorted into intraluminal vesicles that undergo back fusion with the endosomal membrane allowing sequestered EF and LF to reach the cytosol (Abrami et al., 2004).

The toxicity of LT and ET results from the catalytic activities of LF and EF. LF is a zinc-dependent metalloprotease that cleaves mitogen activate protein kinase (MAPK) kinases (MKK) 1-4 and 6-7, preventing the activation of the ERK1/2, p38 and JNKpathways (Duesbery et al., 1998; Pellizzari et al., 1999; Vitale et al., 2000; Tournier et al., 2005) and thus interfering with critical signaling pathways involved in host defense (Figure 2). EF is a calmodulin- and $\mathrm{Ca}^{2+}$-dependent adenylate cyclase that causes a sustained increase of cAMP (Leppla, 1982) by converting ATP to cAMP. As discussed above in the context of the ACT from $B$. pertussis, increased cAMP levels perturb key cellular functions, leading to severe consequences for the host (Leppla, 1982; Firoved et al., 2005).

\section{Anthrax toxins: Weapons to Cripple Host Macrophages and Neutrophils}

Anthrax has for long been described as a toxin-mediated disease, mainly because LT and ET can be lethal for experimental animals and anti-toxin immunization is effective in protecting against infection (Kaur et al., 2013). However, it has recently been proposed that extreme bacteraemia and severe sepsis rather than the anthrax toxins per se are the cause of anthraxinduced lethality (Coggeshall et al., 2013). Indeed, the fact that anthrax toxins act on multiple tissues simultaneously, due to the ubiquitous expression of the anthrax toxin receptors, complicate untangling their effects on the host and delayed the identification of the key tissue targets responsible for its lethal effects. Recently, using cell-type specific CMG2-null mice and the correspondent 


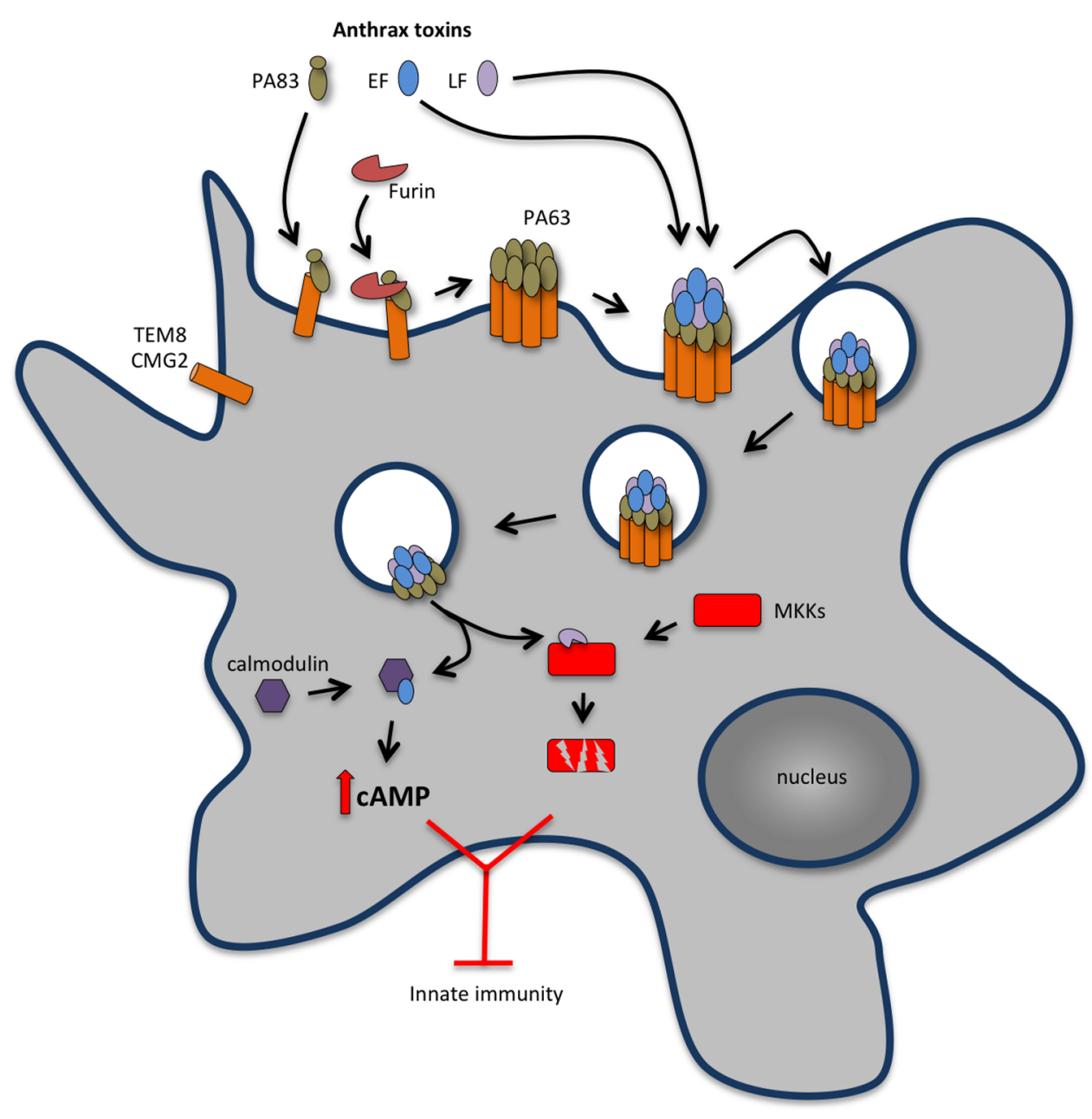

FIGURE 2 | Anthrax toxins cooperatively disable host innate immune response. Host cell intoxication by anthrax toxins involves interaction of protective antigen (PA, $83 \mathrm{kDa}$ ) with two cellular receptors [tumor endothelium marker 8 (TEM8), also known as anthrax toxin receptor 1 (ANTXR1) and capillary morphogenesis protein 2 (CMG2) also known as anthrax toxin receptor 2 (ANTXR2)], which are expressed by different cell types, including macrophages and neutrophils. Upon binding to the cell surface receptor, PA83 is proteolytically processed at its $\mathrm{N}$-terminus by a furin-like protease yielding the C-terminal fragment PA63 that oligomerises into a heptameric prepore able to bind edema factor (EF) and lethal factor (LF). The EF and/or LF-prepore-receptor complex undergoes receptor-mediated endocytosis and the acidic conditions in endosomes induce conversion of the prepore to a pore, allowing translocation of EF and LF into the cell cytosol to exert their cytotoxic effects. LT is a zinc-dependent metalloprotease that inhibits activation of neutrophils and macrophages, expression of inflammatory cytokines and cell motility by disrupting mitogen activated protein kinase kinases (MAPKKs)-regulated pathways. LT activity also promotes macrophage apoptosis by interfering with pro-survival MAPKK dependent pathways. ET is a calcium and calmodulin-dependent adenylate cyclase that increases intracellular cAMP

concentration, leading to the suppression of the expression of inflammatory cytokines and cell chemotaxis through protein kinase A (PKA)-dependent pathways. The concerted action of LT and ET blocks the function of phagocytic cells.

cell-type specific CMG2-expressing mice, Liu and colleagues have shown that LT-induced mortality requires targeting of cardiomyocytes and vascular smooth muscle cells, whereas ETinduced lethality relies mainly on targeting hepatocytes (Liu et al., 2013). Using myeloid-specific CMG2-null mice, in which both macrophages and neutrophils are insensitive to LT and ET due to their inability to bind and internalize the toxins, the same authors have also clarified the role of macrophages and other myeloid cells in anthrax toxins induced lethality and in $B$. anthracis infection (Liu et al., 2010). Myeloid-specific CMG2-null mice are fully sensitive to both LT and ET, indicating that lethality does not depend on the targeting of macrophages, neutrophils, and other myeloid cells (Liu et al., 2010). However, they are completely resistant to infection by $B$. anthracis, indicating that the targeting of myeloid cells by anthrax toxins is required for the establishment of a successful infection (Liu et al., 2010). In what concerns the relative contributions of ET and LT to the establishment of $B$. anthracis infection, trials with Sterne strains deleted of PA, LF, or EF suggest that LT plays a more prominent role (Liu et al., 2010).

Available data indicate that LT and ET act in concert to inhibit macrophage activation as well as the activation and recruitment of other immune cells, such as neutrophils, early in infection (Baldari et al., 2006; Tournier et al., 2009; Liu 
et al., 2014). This favors bacterial escape and multiplication, and contributes to the severe bacteraemia observed in terminal disease. Macrophage activation requires signaling through MAPK cascades, including JNK and p38 pathways, which are central for induction of inflammatory molecules, including cytokines and chemoattractants, as well as Cox-2 and iNOS. LT interrupts MAPK cascades by directly cleaving MAPKK, whereas ET inhibits MAPK-dependent gene expression by interfering with multiple PKA-related pathways (Baldari et al., 2006). Several reports show that LT inhibits the secretion of pro-inflammatory cytokines by macrophages as well as by DCs in vitro and in vivo (Pellizzari et al., 1999; Erwin et al., 2001; Agrawal et al., 2003; Alileche et al., 2005; Bergman et al., 2005; Brittingham et al., 2005; Tournier et al., 2005; Ribot et al., 2006). ET has been shown to suppress secretion of inflammatory mediators by DCs (Tournier et al., 2005). Whereas LT inhibits IL-10 secretion by these cells, ET inhibits IL12p70 production (Tournier et al., 2005). Interestingly, LT and ET have a cumulative suppressive effect upon TNF $\alpha$ secretion (Tournier et al., 2005). In addition to suppress proinflammatory cytokine secretion by macrophages, LT is also able to trigger programmed cell death in these cells in vitro. Indeed, it has been reported that LT induced apoptosis of RAW264.7 cells (Popov et al., 2002). Furthermore, although treatment of three different human monocytic cell lines (HL-60, THP-1, and U937) did not result in cell death, upon differentiation into macrophage-like phenotypes, the cells become susceptible to a cell death program that has features of apoptosis but apparently does not requires the activity of effector caspases (Kassam et al., 2005). The apoptogenic activity of LT toward macrophages likely relates to LT-dependent disruption of survival signals triggered by TLR4 and mediated by p38 MAPK (Park et al., 2002, 2005; Hsu et al., 2004) that activates the NF-kB-dependent expression of pro-survival genes. By cleaving the upstream MAPKK MKK3, LT blocks p38 MAPK and NF-kB activation, leading to macrophage apoptosis (Huang et al., 2004; Park et al., 2005).

Lethal toxin has also been shown to induce a rapid and lytic form of caspase-1-dependent cell death, called pyroptosis, in macrophages from specific rat and mice strains. The susceptibility of macrophages to pyroptosis has been linked to polymorphisms of the Nlrp1b gene in mice (Boyden and Dietrich, 2006) and of the orthologous Nlrp1 gene in rat (Newman et al., 2010). The ability of LT to induce macrophage pyroptosis was initially interpreted as a virulence mechanism of $B$. anthracis (Muehlbauer et al., 2007). It was speculated that the destruction of macrophages by LT compromised their role in restricting B. anthracis infection and that the cytokine burst associated to LT-induced macrophage lysis contributed to LT-dependent pathological effects by aggravating the vascular damage occurring in anthrax (Muehlbauer et al., 2007). More recently, it has been shown that LT is able to directly cleave mouse Nlrp1b and rat Nlrp1 close to their N-terminus (Hellmich et al., 2012; Levinsohn et al., 2012; Chavarria-Smith and Vance, 2013) resulting in the activation of Nlrp1 inflammasomes in rat and in mice with LT-sensitive macrophages. Ultimately, this leads to caspase-1 activation and pyroptosis accompanied by the release of the inflammatory cytokines IL-1 $\beta$ and IL-18, which induces a strong innate immune response that is protective against B. anthracis infection (Moayeri et al., 2010; Terra et al., 2010). Therefore, the current view is that LT-mediated activation of Nlrp1 that leads to inflammasome activation and macrophage pyroptosis is not a virulence mechanism used by $B$. anthracis to promote infection, but rather a protective host-response against anthrax (Chavarria-Smith and Vance, 2015).

Neutrophils play a major role in controlling B. anthracis infection and anthrax-toxin mediated neutralization of neutrophil functions is essential for successful infection (Liu et al., 2010). In vitro studies suggest that by reducing F-actin formation, LT and ET cooperate to inhibit neutrophil chemotaxis, chemokinesis, and ability to polarize (During et al., 2005, 2007; Szarowicz et al., 2009). It was also reported that neutrophils intoxicated with ET have reduced phagocytic activity (O'Brien et al., 1985). Additionally, LT has been shown to suppress cytokine production by neutrophils in vitro (Barson et al., 2008) and LT and ET were found to block neutrophil priming by LPS or muramyl dipeptide, thereby dampening the oxidative burst normally elicited by bacterial products and required for full antimicrobial activity (Wright and Mandell, 1986). In the case of ET, it has been shown that the inhibition of superoxide production results from an impairment of the activation of the neutrophil NADPH oxidase, an effect that likely results from the activity of ET as an adenylate cyclase (Crawford et al., 2006). Although it has been proposed that these effects are due to the ET-induced rise in CAMP leading to phosphorylation (activation) of PKA (Szarowicz et al., 2009), the downstream targets remain to be identified.

It is now unquestionable that anthrax toxins are crucial in anthrax pathogenesis, but their precise roles during human anthrax infections remain to be further clarified. Following the discovery of the anthrax toxins more than half a century ago, a myriad of studies were developed aiming at defining their role in anthrax disease and lethality. However, most of the infection studies were performed in animal models that may not completely reflect the events occurring during human infections. Concerning the data documenting the immunomodulatory effects of the anthrax toxins, most were obtained in vitro, often in experimental set-ups that involve the use of purified toxins and do not allow examining intoxication in the context of infection. Therefore, the available data need to be validated in the context of relevant animal models of infections before being extrapolated to the human disease scenario.

\section{Photobacterium damselae piscicida: KILLING TWO BIRDS WITH ONE STONE}

Photobacterium damselae piscicida is a Gram-negative extracellular bacterium that causes a systemic and deadly infection with a rapid course and very high mortalities in both wild and cultured marine fish (Romalde, 2002; Barnes et al., 2005). Phdp infections are characterized by the occurrence of generalized bacteraemia and extensive cytopathology with abundant tissue necrosis (do Vale et al., 2007). Infected fish often present whitish tubercle-like lesions of about 0.5 to 
$3.5 \mathrm{~mm}$ in diameter in several internal organs (Tung et al., 1985; Hawke et al., 1987; Noya et al., 1995; Magariños et al., 1996; do Vale et al., 2007), leading to the coining of the disease as fish pseudotuberculosis (Kubota et al., 1970). The lesions consist of accumulations of bacteria and apoptotic and necrotic cell debris (Kubota et al., 1970; Hawke et al., 1987; do Vale et al., 2007).

Photobacterium damselae piscicida-associated pathology is triggered by AIP56 (apoptosis inducing protein of $56 \mathrm{kDa}$ ), a plasmid-encoded toxin secreted by virulent Phdp strains (do Vale et al., 2005). The toxin is systemically disseminated in infected animals and induces selective apoptotic destruction of macrophages and neutrophils (do Vale et al., 2003, 2005, 2007). The simultaneous destruction of these cell types by AIP56 has two dramatic consequences for the host. On one hand, the drastic reduction of the number of phagocytes impairs the phagocytic defense, favoring pathogen dissemination (do Vale et al., 2007). On the other hand, it compromises the host capacity to clear apoptosing cells, leading to the lysis of the phagocytes by postapoptotic secondary necrosis with consequent release of their highly cytotoxic tissue-damaging contents (do Vale et al., 2007; Silva et al., 2008).

\section{AIP56: Spreading the Misery by Killing the Soldiers and Preventing their Burial}

AIP56 is the founding and the only characterized member of a continuously growing family of bacterial proteins identified in different organisms, mainly marine Vibrio species and Arsenophonus nasoniae. It is an AB-type toxin, possessing a catalytic A domain at its $\mathrm{N}$-terminal region and a $\mathrm{B}$ domain involved in binding/internalization into target cells at its C-terminal region (Silva et al., 2013; Figure 3). The catalytic domain of AIP56 is a zinc-dependent metalloprotease that cleaves the p65 subunit of NF- $\kappa$ B (Silva et al., 2013), an evolutionarily conserved transcription factor that regulates the expression of inflammatory and anti-apoptotic genes, playing a key role in host responses to microbial pathogen invasion. AIP56 has likely originated from a fusion of two components: its A domain is related to NleC, a type III secreted effector present in several enteric pathogenic bacteria (Yen et al., 2010; Baruch et al., 2011; Pearson et al., 2011; Sham et al., 2011; Hodgson et al., 2015) that are associated with severe human illness and death worldwide, whereas its B domain is related to a protein of unknown function from the lambda-like bacteriophage APSE2, a phage that infects Hamiltonella defensa (Degnan et al., 2009).

Although mammals are not susceptible to Phdp infection, likely due to temperature and osmolality restrictions, AIP56 is able to intoxicate mouse bone marrow derived macrophages (mBMDM; Pereira et al., 2014), through a mechanism similar to the one operating during intoxication of fish cells. Upon encountering susceptible cells, AIP56 binds to a still unidentified cell-surface receptor and is internalized through clathrinmediated endocytosis (Pereira et al., 2014; Figure 3). Once in early endosomes, the toxin either follows the recycling pathway back to the extracellular medium or undergoes low $\mathrm{pH}$-induced translocation across the endosomal membrane into the cytosol to display its toxic activity (Pereira et al., 2014). AIP56 cleaves an evolutionarily conserved peptide bond of the Rel homology domain of NF- $\kappa \mathrm{B}$ p65, removing residues crucial for p65-DNA interaction and compromising NF- $\kappa$ B activity (Silva et al., 2013; Figure 3). During intoxication, the proteolytic activity of AIP56 results in a complete depletion of p65 and leads to the apoptotic death of cells (Silva et al., 2013; Pereira et al., 2014) through a process involving quick activation of caspases-8, -9 and -3 , loss of mitochondrial membrane potential, translocation of cytochrome c to the cytosol and overproduction of ROS (do Vale et al., 2007; Reis et al., 2007a,b, 2010; Costa-Ramos et al., 2011).

AIP56 plays a pivotal role in the establishment of Phdp infection and in the development of the infection-associated pathology. In the initial phase of Phdp infection, when local multiplication of Phdp becomes detectable in infected tissues, extensive infiltration of macrophages and neutrophils occurs (do Vale et al., 2007). As the infection progresses, the pathogen extensively multiplies and disseminates systemically, which leads to a septicemic situation paralleled by the occurrence of AIP56 in the systemic circulation (do Vale et al., 2007). The presence of circulating toxin correlates with the appearance of high numbers of apoptotic macrophages and neutrophils in the peripheral blood, in the spleen, liver, and head-kidney vasculature, as well as in the splenic and head-kidney parenchyma and gut lamina propria (do Vale et al., 2007). This systemic apoptotic destruction of macrophages and neutrophils triggered by AIP56 explains the extensive phagocyte depletion observed in advanced Phdp infections (do Vale et al., 2007). The ability of the toxin to neutralize the main players responsible for the phagocytic defense of the host is a very effective pathogenicity strategy that contributes to the severity of Phdp infections by promoting survival of the pathogen and its unrestricted extracellular multiplication. Concomitantly, the AIP56-induced apoptosis of both professional phagocytes leads to tissue damage with deleterious consequences for the host. In fact, the destruction of macrophages, the cells with the crucial role of eliminating apoptotic cells (Parnaik et al., 2000; Wood et al., 2000), compromises the efficient clearance of apoptotic phagocytes and leads to their lysis by secondary necrosis (do Vale et al., 2003) with release of their cytotoxic intracellular contents (do Vale et al., 2007). This has particularly serious consequences in the case of neutrophils, due to their richness in highly cytotoxic molecules, which damage many cell types and produce tissue injury, thus contributing to the genesis of the Phdp-associated cytopathology.

\section{Staphylococcus aureus: A BENCH OF SECRETED MOLECULES TO SHOOT NEUTROPHILS}

Staphylococcus aureus is a Gram-positive bacterium that often colonizes the human nares and the skin. Besides being a commensal, $S$. aureus is also a redoubtable human pathogen that causes a variety of severe diseases. To set up a successful infection, $S$. aureus evolved an amazing variety of immune evasive strategies wiping out both innate and adaptive immune responses. S. aureus infections involve the invasion of host tissues, replication in 


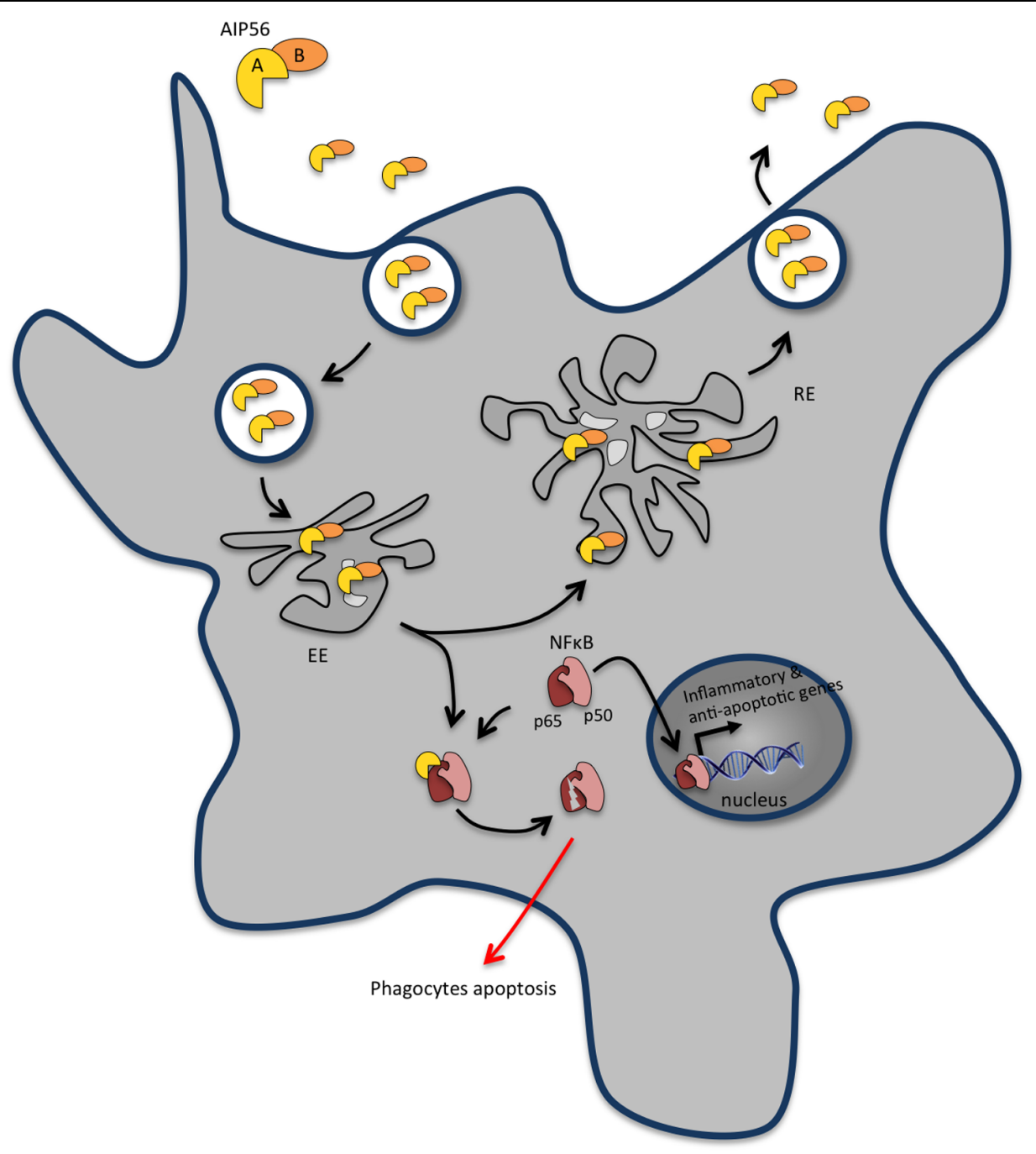

FIGURE 3 | AIP56 blocks innate immunity by inducing massive apoptosis of host macrophages and neutrophils. Upon encountering susceptible cells, apoptosis-inducing protein of $56 \mathrm{kDa}$ (AIP56) binds to a still unidentified cell-surface receptor and undergoes clathrin-mediated endocytosis. Once in early endosomes, the toxin either follows the recycling pathway back to the extracellular medium or suffers low pH-induced translocation across the endosomal

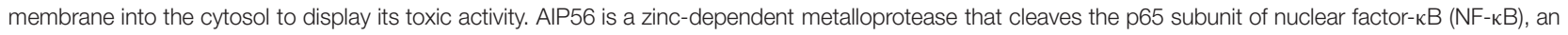
evolutionarily conserved transcription factor that regulates the expression of inflammatory and anti-apoptotic genes and plays a key role in host responses to microbial pathogen invasion. During infection, AIP56 disseminates systemically and its activity leads to depletion of macrophages and neutrophils by post-apoptotic secondary necrosis, thereby blocking the phagocytic defense of the host and contributing to the occurrence of tissue damage.

abscess lesions and dissemination through purulent drainage of these lesions and require the recruitment of immune cells to the site of infection. Such infiltrated immune cells would usually eliminate the bacteria. However, to counter their action, $S$. aureus secretes soluble molecules targeting multiple pathways to manipulate the capacity of neutrophils for chemotaxis, phagocytosis, and bacterial killing, thus enabling pathogen replication and ensuring the success of the infection. Several recent and comprehensive reviews highlight how $S$. aureus virulence factors manipulate the host immune response (Spaan et al., 2013b; Otto, 2014; Thammavongsa et al., 2015). Here we will focus on its secreted molecules mainly targeting neutrophils, modulating their function, or inducing cell killing.

\section{Avoiding Neutrophil Extravasation, Chemotaxis, and Activation}

In general, upon pathogen recognition, pro-inflammatory signals released by resident macrophages promote the adhesion of circulating neutrophils and further extravasation across capillary endothelium to the site of infection. This process relies on interactions between the endothelial surface receptors (e.g., selectins and ICAM1) and their respective ligands on the surface of neutrophils (e.g., PSGL1 and $\beta 2$-integrin) (Spaan et al., 2013b). To inhibit neutrophil recruitment to the infected tissues, S. aureus secretes two anti-inflammatory factors that prevent neutrophil adhesion to the blood vessels and further transmigration (Figure 4A). The staphylococcal SSL5 binds 
PSGL1 in a glycan dependent manner at the surface of neutrophils, blocking its interaction with P-selectin expressed by endothelial cells and abrogating the early steps of neutrophil attachment (Bestebroer et al., 2007). In addition, SSL5 was shown to inactivate matrix metalloproteinase from human neutrophils, accounting for the limited capacity of neutrophils to transmigrate into infected tissues (Itoh et al., 2010). The extracellular adherence protein (Eap) recognizes endothelial ICAM1, preventing its interaction with $\beta 2$-integrins at the surface of neutrophils and further inhibiting extravasation (Chavakis et al., 2002).

Staphylococcus aureus also secretes a number of antagonists of neutrophil receptors interfering with chemokine signaling and limiting neutrophil recruitment (Figure 4A). In particular, SSL5 directly binds the $\mathrm{N}$-terminus of G-protein coupled chemokine receptors (GPCRs) inhibiting calcium mobilization and actin polymerization, thus impairing neutrophil responses to a huge diversity of chemokines (e.g., CXCL8, CXCL1, CCL2, and CCL5) and to complement fragments C3a and C5a (Bestebroer et al., 2009). Similarly to the recognition of PSGL1 by SSL5, binding to GPCRs relies on the presence of sialic acid residues (Baker et al., 2007; Bestebroer et al., 2007, 2009). In addition, SSL5 was shown to bind to platelet glycoproteins, inducing platelet activation and aggregation, which could be important for colonization and immune evasion by S. aureus (de Haas et al., 2009). SSL10 inhibits CXCL12-mediated responses by targeting CXCR4 (Walenkamp et al., 2009) and SSL3 binds to TLR2, hindering immune recognition of staphylococcal lipoproteins and peptidoglycan (Yokoyama et al., 2012).

Phenol-soluble modulins are produced by all $S$. aureus strains and have multiple roles in staphylococcal pathogenesis (Cheung et al., 2014a). In particular, PSMs are potent pro-inflammatory molecules that interact with human formyl peptide receptor 2 (FPR2) (Kretschmer et al., 2010), a GPCR involved in the recognition of pathogens. At nanomolar concentrations, PSMs bind to and activate FPRs, with the strongest activation occurring through FPR2, stimulating several FPRs effector functions such as chemotaxis and pro-inflammatory cytokine production (e.g., CXCL8; Fu et al., 2006). However, human isolates of S. aureus evolved other strategies to counter neutrophil chemotaxis by directly interfering with FPRs signaling and limiting cytotoxicity while promoting bacterial replication (McCarthy and Lindsay, 2013; Cheung et al., 2014b). Inhibition of FPRs-mediated pro-inflammatory signaling occurs via the secretion of the chemotaxis-inhibitor protein of $S$. aureus (CHIPS) (de Haas et al., 2004) and the FPR2/ALS-inhibitory protein (FLIPr) and its homologue FLIPrL (Prat et al., 2006, 2009; Figure 4A). While CHIPS binds and inhibits FPR1 and C5aR, FLIPr and FLIPrL block FRP2-mediated signaling, thus avoiding recognition of PSMs secreted by $S$. aureus, impairing proinflammatory response and reducing neutrophil recruitment (Haas et al., 2004, 2005; Prat et al., 2006, 2009). Clearly, CHIPS, FLIPr and FLIPrL, and PSMs have opposite effects on FPRs activation. Thus the production/secretion of these bacterial molecules is likely to be under strict control to allow the establishment of the infection and to evade immune recognition.
The repertoire of secreted molecules by $S$. aureus to evade the early steps of immune response also include Stathopain A (ScpA), a cysteine protease that specifically cleaves the N-terminus of human CXCR2 (Laarman et al., 2012), a GPCR responding to several chemokines (e.g., CXCL1-3 and CXCL5-8). Stathopain A inhibits CXCR2-mediated calcium mobilization, migration, intracellular signaling and activation of neutrophils (Laarman et al., 2012), appearing as an important immunomodulatory molecule causing neutrophil unresponsiveness to several chemokines and blocking their recruitment to the site of infection.

\section{Blocking Complement Activation, Opsonization, and Phagocytosis}

Staphylococcus aureus display intrinsic physical features (e.g. thick peptidoglycan layer and capsule) that confer resistance to complement-mediated killing and neutrophil phagocytosis. In addition, $S$. aureus secretes a variety of highly specific proteins with complement-modulating functions (Figure 4B), thereby delaying the innate immune attack and generating a window of opportunity to replicate and establish within the host (Spaan et al., 2013b; Thammavongsa et al., 2015). Several of these secreted molecules target C3 or C3 convertases, both central molecules in the complement activation cascade. Aureolysin is a metalloproteinase that cleaves $\mathrm{C} 3$, generating a modified $\mathrm{C} 3 \mathrm{~b}$ fragment that is further degraded instead of being covalently linked to the bacterial surface where it would promote the generation of the chemoattractant molecule C5a (Laarman et al., 2011). In addition, this proteinase degrades human antimicrobial peptides highly potent against $S$. aureus (Sieprawska-Lupa et al., 2004). Thus, aureolysin activity promotes infection by blocking the complement cascade impairing bacterial C3b opsonization, phagocytosis, and neutrophil-mediated killing (Sieprawska-Lupa et al., 2004; Laarman et al., 2011). Staphylococcal component inhibitor (SCIN) specifically binds to human C3 convertase and blocks its activity thereby preventing the production of $\mathrm{C} 3 \mathrm{a}, \mathrm{C} 3 \mathrm{~b}$, and $\mathrm{C} 5 \mathrm{a}$, thus interfering with complement activation and with neutrophil-mediated killing of $S$. aureus (Rooijakkers et al., 2005a, 2009; Figure 4B). In addition, S. aureus secreted extracellular fibrinogen-binding protein (Efb) together with its homologue extracellular complement-binding protein (Ecb), were shown to inhibit both $\mathrm{C} 3$ and $\mathrm{C} 5$ convertases (Jongerius et al., 2010a,b, 2007). Other S. aureus secreted proteins target both $\mathrm{C} 3$ and immunoglobulin binding, thus impairing complement activation and opsonization, this is the case of staphylococcal binder of immunoglobulin (Sbi; Haupt et al., 2008) and staphylokinase (Rooijakkers et al., 2005b).

Besides their role in blocking neutrophil extravasation and chemotaxis (described above), some SSLs also hinder complement activation and phagocytosis. SSL7 binds IgA and complement $\mathrm{C} 5$, inhibiting the production of $\mathrm{C} 5 \mathrm{a}$ and further phagocytosis and bacterial clearance during in vivo infection (Bestebroer et al., 2010). SSL10 binds to IgG1 preventing recognition by $\mathrm{Fc}$ Receptors (FcR), thus impairing IgG1 opsonization and phagocytosis (Patel et al., 2010; Figure 4B). 


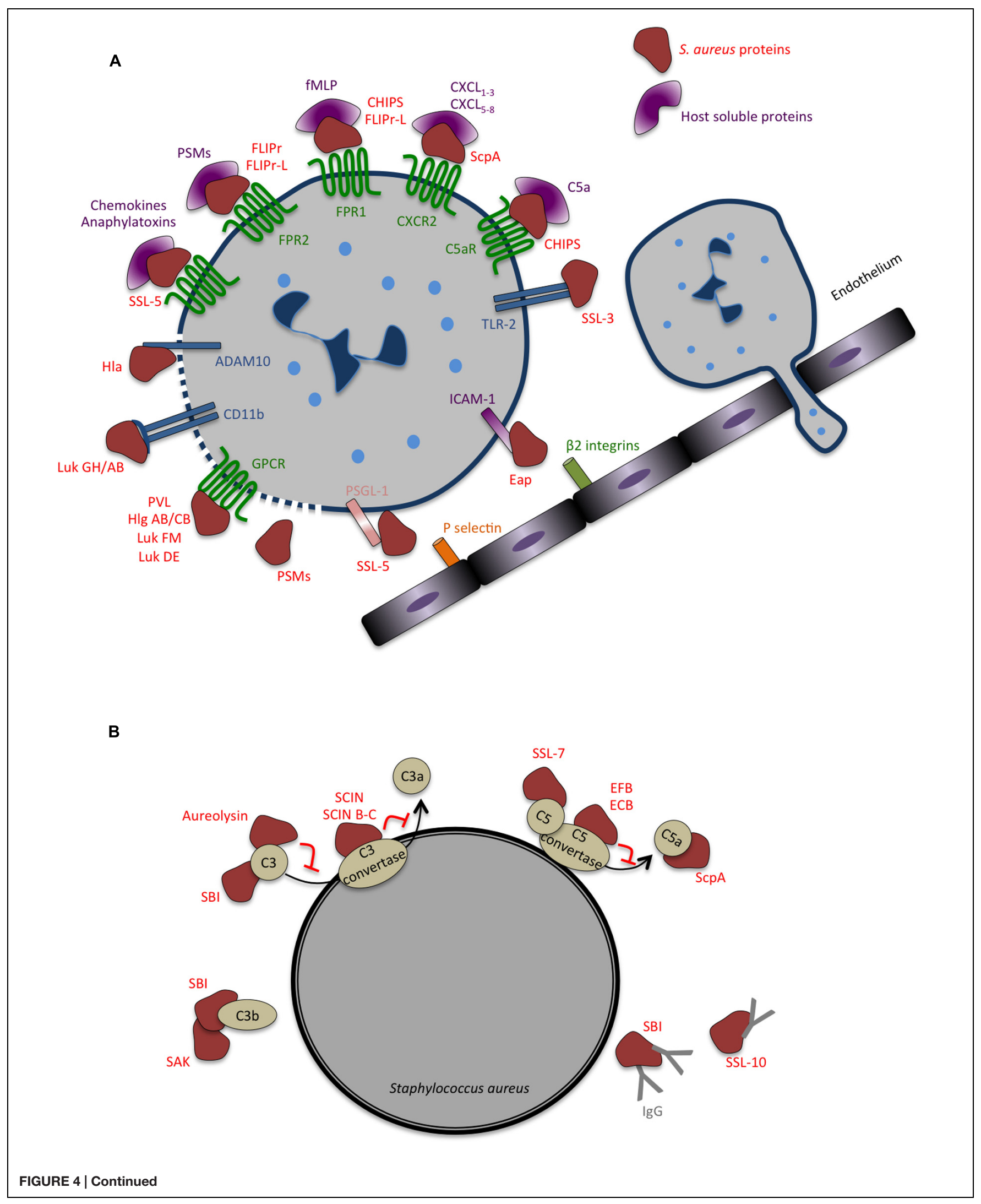




\begin{abstract}
FIGURE 4 | Continued
Strategies evolved by Staphylococcus aureus to counteract innate immune response. (A) Secreted bacterial factors that inhibit neutrophils extravasation, chemotaxis and activation. Neutrophil rolling is modulated by staphylococcal superantigen-like 5 (SSL5) that binds P-selectin glycoprotein ligand-1 (PSGL-1), blocking its interaction with P-selectin. The adhesion of neutrophils to the endothelium and consequent transmigration is inhibited by extracellular adherence protein (Eap), which binds to intercellular adhesion molecule 1 (ICAM-1). In addition to inhibiting PSGL-1, SSL5 inhibits neutrophil responses to chemokines and to anaphylatoxins, by binding to different chemokine receptors. Several staphylococcal molecules impair neutrophil chemotaxis and important co-signaling events during migration and phagocytosis: chemotaxis-inhibitor protein of S. aureus (CHIPS) binds and inhibits formyl peptide receptor 1 (FPR1) and C5a receptor (C5aR); formyl peptide receptor-like 1 inhibitor (FLIPr)-like inhibit FPR1; FLIPr and FLIPr-like inhibit FPR2; staphopain (ScpA) cleaves Chemokine (C-X-C Motif) Receptor 2 (CXCR2); staphylococcal SSL3 inhibits toll-like receptor 2 (TLR2)-mediated signaling, the bicomponent leukocidins Panton-Valentine leukocidin (PVL), gamma-hemolysin (HIg) ABC, leukocidin (Luk) FM, Luk GH/AB, and Luk DE interact with chemoattractant receptors of the G-protein-coupled receptor (GPCR) family. Both Hla and Luk GH/AB induce cell lysis by binding ADAM metallopeptidase domain 10 (ADAM10) and CD11b, respectively. The cytolytic peptides phenol-soluble modulins (PSMs) have an amphipathic alpha-helical region that likely contributes to their lytic activity, presumably by membrane insertion and pore formation. (B) Secreted bacterial factors that inhibit opsonization and phagocytosis by neutrophils. The secreted metalloprotease aureolysin inhibits phagocytosis and killing of bacteria by neutrophils by cleaving C3. Staphylococcal complement inhibitor (SCIN), SCIN-B, and SCIN-C associate with and inhibits C3 convertase, thereby preventing the production of $\mathrm{C} 3 \mathrm{a}, \mathrm{C} 3 \mathrm{~b}$, and further $\mathrm{C} 5 \mathrm{a}$ and consequently interfering with complement activation. The extracellular fibrinogen binding protein (EFB) and the extracellular complement-binding protein (ECB) also inhibit complement activation by inactivating C5 convertase and staphylococcal SSL7 targets C5. Staphylococcal binder of immunoglobulin (SBI) affect both the function of complement and immunoglobulin binding, blocking the classical complement activation pathway, and associates with C3 inhibiting the alternative pathway. Staphylokinase (SAK) forms enzymatically active complexes with C3b blocking complement activation. Staphylococcal SSL10 binds IgG, affecting FC receptor (FCR) recognition and complement activation.
\end{abstract}

\section{Avoiding NET Bactericidal Activities}

In addition to phagocytosis and intracellular killing, neutrophils evolved an alternative defense mechanism to trap extracellular pathogens and prevent their dissemination. This strategy relies on the release of nuclear content together with antimicrobial cytosolic and granular proteins to form neutrophil extracellular traps (NETs), which are scaffolds that act as physical barriers to pathogen progression protecting host tissues from damage (Papayannopoulos and Zychlinsky, 2009). A secreted staphylococcal nuclease (Nuc) has the capacity to degrade NETs thereby allowing $S$. aureus to resist their bactericidal activities in vitro as well as in a respiratory tract infection model (Berends et al., 2010). NET degradation by Nuc leads to the production of monophosphate nucleotides that are further converted into deoxyadenosine through the activity of adenosine synthase (AdsA), another $S$. aureus secreted protein. Interestingly, the accumulation of deoxyadenosine generated by AdsA activity promotes the autocleavage of pro-caspase-3, triggering caspase-3-induced apoptosis of infiltrating macrophages (Thammavongsa et al., 2013). Together, staphylococcal Nuc and AdsA act in a concerted mode to promote bacterial survival in $S$. aureus abscesses, by excluding macrophages from the infection foci.

\section{Neutrophil Killing: The Ultimate Defense}

In line with its ability to evade almost every step of the innate immune response, $S$. aureus induce the death of innate immune cells, trough the secretion of PSMs and several other toxins. As mentioned above, PSMs are $S$. aureus secreted molecules with multiples roles in infection (Wang et al., 2007; Cheung et al., 2014a). They trigger inflammatory responses by interacting with FPR2 and display, at higher concentrations, FPR2-independent cytolytic activity likely through membrane insertion and pore formation (Kretschmer et al., 2010; Figure 4A). In particular, PSM $\alpha$ peptides are able to trigger the lysis of the phagosome after neutrophil ingestion allowing intracellular bacterial replication, and ultimately are responsible for lysis of neutrophils promoting bacterial survival and escape to the extracellular milieu (Wang et al., 2007; Geiger et al., 2012; Chatterjee et al., 2013; Grosz et al., 2014). In vitro, expression levels of PSMs correlate with levels of cytotoxicity (Rasigade et al., 2013). Moreover, mutants deficient for PSM $\alpha$ production are perturbed in biofilm formation (Peschel and Otto, 2013) and attenuated in the mouse bloodstream infection model (Wang et al., 2007). Altogether, these observations strongly suggest that PSM $\alpha$ triggered effects may play a key role in in vivo $S$. aureus infection.

In addition to PSMs whose cytolytic activity is receptorindependent, $S$. aureus secretes other cytolytic toxins that interact with specific receptors at the surface of eukaryotic cells, oligomerize and form pores inducing cell leakage and ultimately total lysis. S. aureus-produced toxins targeting white blood cells belong to the beta-barrel pore-forming toxins and comprise hemolysin- $\alpha$ (Hla, also called $\alpha$-toxin) and bicompetent leukocidins (Otto, 2014; Thammavongsa et al., 2015; Figure 4A). In vivo infection studies have shown that Hla is required for several S. aureus-associated pathologies, such as pneumonia and severe skin infections (Bubeck Wardenburg et al., 2007; Bubeck Wardenburg and Schneewind, 2008; Kennedy et al., 2010). Hla interacts with high affinity with ADAM10 at the surface of host cells (Wilke and Bubeck Wardenburg, 2010) to damage epithelial, endothelial and immune cells (Berube and Bubeck Wardenburg, 2013; Figure 4A). Mice lacking ADAM10 expression in the lung epithelium resist to lethal pneumonia (Becker et al., 2014), whereas animals lacking ADAM10 specifically on myeloid lineage develop exacerbated skin infections (Inoshima et al., 2011). Although these results suggest that the outcome of Hlamediated effects may dependent on the infected tissue, the role of Hla on tissue-specific innate immunity requires further analysis.

Leukocidins are composed by two distinct and independently secreted subunits that form heteromultimeric pores in the membrane of host myeloid cells (Otto, 2014). S. aureus produce different arrays of leukocidins with different species and cell type specificities, which are mainly dictated by their 
interaction with host GPCRs (Spaan et al., 2013b; Otto, 2014; Thammavongsa et al., 2015; Figure 4A). In vitro assays with purified proteins, as well as ex-vivo infections with $S$. aureus, have shown that leukocidin $\mathrm{AB}$ (LukAB, also called LukGH) kills human, but not mouse, neutrophils upon binding to CD11b (DuMont et al., 2013a). In addition, purified LukAB induce the release of NETs (Malachowa et al., 2013) and also promotes the escape from the phagosome in neutrophils, thus enabling S. aureus replication (DuMont et al., 2013b). Gamma-hemolysin HlgAB and HlgCB bind chemokine receptors (e.g., CXCR1, CXCR2, and CCR2) and complement receptors (e.g., C5aR), respectively (Spaan et al., 2014), and promote the lysis of human neutrophils and macrophages in vitro. LukED, produced by a large majority of clinical isolates of S. aureus, triggers the lysis of neutrophils and macrophages of different vertebrates by binding chemokine receptors such as CCR5, CXCR1 and CXCR2 (Alonzo et al., 2013; ReyesRobles et al., 2013). Importantly, LukED was shown to play a critical role in $S$. aureus systemic infections in mice, by promoting bacterial replication in vivo through direct killing of neutrophils (Alonzo et al., 2012). Lastly, Panton-Valentine leukocidin (PVL), which is secreted by a small percentage of S. aureus isolates, binds $\mathrm{C} 5 \mathrm{aR}$ on neutrophils and macrophages and has a restricted activity toward human and rabbit cells (Spaan et al., 2013a, 2015). Despite the several attempts to evaluate the exact contribution of each of these toxins to S. aureus-associated pathologies, their vast species and cell type specificities have rendered this analysis highly challenging. In this context, the data obtained from commonly used animal infection models (e.g., mice and rats) should be interpreted with caution.

\section{Mycobacterium ulcerans: SABOTAGE OF THE HOST IMMUNE RESPONSE BY A POLYKETIDE TOXIN}

Mycobacterium ulcerans is the causative agent of Buruli ulcer, a chronic ulcerative skin disease that usually starts as painless nodules on the limbs that then develop into large ulcers. These can lead to severe scars and local deformities, including disabling contractures, if not treated at early stages (WHO Buruli ulcer fact sheet $\mathrm{N}^{\circ}$ 199, Updated July 2014). Buruli ulcer occurs most frequently in children living in tropical environments, near wetlands. The disease is more common in poor and rural areas of Africa but is also found in South America, Asia and Australia. Mycobacterium ulcerans is currently recognized as an environmental pathogen, but its reservoirs and mode of transmission remain doubtful (WHO Buruli ulcer fact sheet $\mathrm{N}^{\circ} 199$, Updated July 2014). Genetically very close to $M$. tuberculosis and $M$. marinum, M. ulcerans is unique among human pathogenic mycobacteria due to the secretion of a lipid toxin, the mycolactone (George et al., 1999; Hong et al., 2008). Mycolactone displays cytotoxic and immunosuppressive activities and is considered the major pathogenicity factor in Buruli ulcer, being essential for $M$. ulcerans virulence, immune modulation, and colonization (George et al., 1999;
Coutanceau et al., 2005; Marsollier et al., 2005; Torrado et al., 2007a, 2010; Simmonds et al., 2009; Guenin-Mace et al., 2011).

In animal models, injection of mycolactone alone is sufficient to cause ulcers similar to those found in infected hosts (George et al., 1999, 2000). Concerning the mechanism of cellular intoxication, it has been proposed that, due to its hydrophobic nature, mycolactone passively diffuses through the plasma membrane (Snyder and Small, 2003; Figure 5). At micromolar concentrations, mycolactone is highly cytotoxic to a variety of mammalian cells, with variable susceptibility levels depending on the cell type (Hall and Simmonds, 2014). The mycolactone cytotoxicity has been linked to its apoptogenic activity. Apoptosis was observed in several cell types incubated in vitro with mycolactone (George et al., 2000; Gama et al., 2014), when primary mouse macrophages were incubated with toxigenic M. ulcerans strains (Oliveira et al., 2005), and in guinea pigs (George et al., 2000) and mice (Oliveira et al., 2005; Torrado et al., 2007b) infected with mycolactone-producing M. ulcerans. More importantly, massive apoptosis has been observed in Buruli ulcer lesions (Walsh et al., 2005). The mycolactone-induced cell death mechanisms appear to be complex and are not completely understood. It has been shown that mycolactone induces cell cycle arrest at the G1/G0-phase (George et al., 1999), but the connection between this effect of mycolactone and its cytotoxicity remains unclear. Early studies on mycolactone reported the occurrence of early actin cytoskeleton rearrangements, cell rounding, and detachment following incubation with the toxin (George et al., 1998, 1999). More recently, studies with $\mathrm{HeLa}$ and Jurkat $\mathrm{T}$ cells have shown that mycolactone induces increased actin polymerisation in intoxicated cells, as a consequence of its binding to the GTPase domain of the actin-cytoskeleton regulator WiskottAldrich syndrome protein WASP (Guenin-Mace et al., 2013). This leads to hyper-activation of WASP and re-localization of the Arp2/3 complex and consequently, to major cytoskeletal rearrangements, including the formation of filopodia (GueninMace et al., 2013). In epithelial cells, this causes loss of cell adhesion and E-cadherin-dependent tight junctions, ultimately leading to the death of detached cells by anoikis (GueninMace et al., 2013). Recent studies performed in vitro with murine fibroblasts confirmed the cytoskeleton as a main target of mycolactone, by showing that mycolactone causes changes in microtubules and affects several regulators and structural components of microtubules and microfilaments (Gama et al., 2014). These deleterious effects inflicted by mycolactone upon the cytoskeleton likely contribute to the formation of the lesions characteristic of Burulli ulcer. Additionally, given the central role of the cytoskeleton in controlling key cellular functions, such as endocytosis, intracellular trafficking, cell adhesion and migration, it is reasonable to speculate that, by highjacking cytoskeleton functions, mycolatone perturbs the functions of phagocytic cells. Indeed, it is likely that the decreased phagocytic activity of macrophages exposed to mycolactone (Adusumilli et al., 2005; Coutanceau et al., 2005) results from the effect of the toxin upon the cytoskeleton of those cells. Further investigations are required to determine whether 


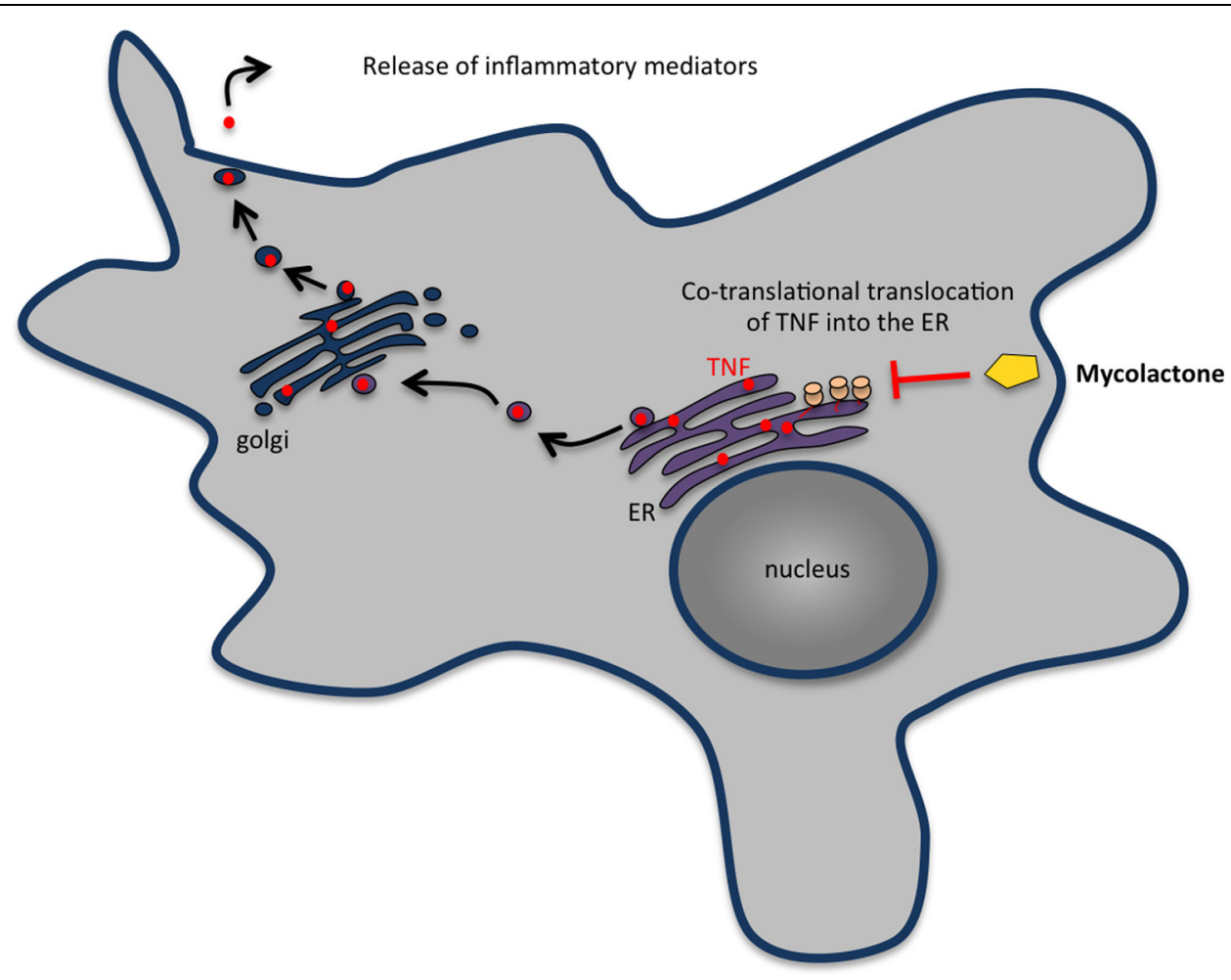

FIGURE 5 | Mycolactone inhibits the secretion of most cytokines, chemokines and other inflammatory mediators by macrophages. In eukaryotic cells, secretory proteins cross the ER membrane before being transported in vesicles to the Golgi complex and then to the plasma membrane. Mycolactone enters cells by passive diffusion through the plasma membrane and inhibits the production of inflammatory mediators by macrophages by blocking the translocation of nascent proteins into the ER. The proteins wrongly accumulated in the cytosol are then degraded by the proteasome.

cytoskeleton is manipulated by mycolactone in macrophages and neutrophils and what are the consequences of this manipulation in vivo.

In addition to its known cytotoxic effects toward distinct cell types, at non-cytotoxic concentrations, mycolactone interferes with important functions of immune cells, including monocytes, macrophages, and DCs (Arango Duque and Descoteaux, 2014; Hall and Simmonds, 2014). It is well recognized that macrophages play crucial roles in mycobacterial infections, including in Buruli ulcer. Although Buruli ulcer histopathology is characterized by extensive areas of necrosis with abundant extracellular bacteria, studies on infected humans, and experimental M. ulcerans infections revealed that M. ulcerans is phagocytosed by macrophages and neutrophils, similarly to the other pathogenic mycobacteria (Torrado et al., 2007b; Silva et al., 2009) and escape the microbicidal activity of the macrophages presumably by mycolactonedependent interference with the IFN $\gamma$-dependent phagosome maturation and NO production required to control M. ulcerans infection (Torrado et al., 2010). After an initial phase of intracellular proliferation, varying according to the strain cytotoxicity/virulence, $M$. ulcerans causes apoptosis/necrosis of the host macrophage through a mycolactone-dependent mechanism and becomes extracellular (Torrado et al., 2007b).
Usually, phagocytosis of a microorganism triggers signaling events that rapidly culminate in a controlled inflammatory response involving the secretion of several cytokines and chemokines that recruit other inflammatory cells to the site of infection. However, available evidence suggests that this early response is heavily perturbed by mycolactone. Indeed, cells exposed to mycolactone-producing strains of $M$. ulcerans secrete much less TNF than those infected with mycolactone-negative strains (Torrado et al., 2007a) and purified mycolactone has been shown to supress the production of several cytokines, chemokines, and other inflammatory mediators by macrophages (Arango Duque and Descoteaux, 2014; Hall and Simmonds, 2014). It has been proposed that this suppression is associated with a mycolactone-induced blockade of co-translational protein translocation into the ER and subsequent degradation of the aberrantly located proteins in the cytosol (Hall et al., 2014; Figure 5). Failure to produce cytokines and chemokines may contribute to the absence of inflammatory infiltrate at the central necrotic areas of the lesion containing high numbers of extracellular bacilli, in addition to the lysis of recruited inflammatory cells induced by the build-up of mycolactone. The inflammatory infiltrates occupy a band at the periphery of the lesion that represents a front that is continuously advancing into healthy tissues in progressive M. ulcerans lesions (Silva et al., 2009). 


\section{CONCLUDING REMARKS}

The clearance of infectious agents greatly depends on the host innate immune responses that take place at early stages of infection and in which macrophages and neutrophils are the central players. To counteract the host defense mechanisms, bacterial pathogens secrete a bench of different toxins that neutralize, at different levels, the host innate immune response and in particular, annihilate the function of macrophages and neutrophils. Despite having different features, secreted toxins targeting the function of innate immune cells often display similar and/or complementary activities and modulate the same central pathways of the host cell (e.g., inflammatory response, cytoskeleton dynamics, and cAMP signaling). Furthermore, a single pathogen may secrete several toxins that act differently to produce the same outcome (e.g., inhibit chemotaxis or induce phagocyte death). These apparently redundant strategies of bacterial attack ensure the multistep impairment of the early host immune responses mounted against the pathogen and guarantee the control of host-pathogen interaction providing a window of time and opportunity for bacterial growth and establishment within the host.

In the past, many studies aiming to uncover the molecular functions of bacterial toxins on host cells were performed in vitro in several cultured cell lines, and more recently in primary cells, using a wide range of concentrations of purified toxins. In addition, studies on animal models (mainly in rodents) using either purified toxins, wild type bacteria and toxindeficient mutants, provided a number of important observations regarding the toxin-mediated pathologies. Together, these studies generated an incredible amount of data that paradoxically poorly contributed to the understanding of the role of toxins in human infections. Whereas in the perspective of using toxins as molecular tools to address cell biology topics there is great value in testing toxin effects in many in vitro cell systems, several issues render extremely difficult the interpretation of data from in vitro studies in the context of infection. In particular, the concentration of purified toxin used is often much higher than that produced by bacteria during infection and it is highly variable among different studies, and the cell lines tested are often non-relevant for the pathophysiology of the infection. Regarding studies performed in animal models, two major concerns have been pointed out: (1) many toxins display species-specificity and thus routinely used models, specially rodents, are non-relevant for the study of many toxin-mediated human pathologies compromising the extrapolation of data and (2) direct inoculation of purified toxins in the animals only provide limited information that do not necessarily recapitulate the effect of a given toxin in the context of human bacterial infection. Thus, the data generated so far

\section{REFERENCES}

Abrami, L., Lindsay, M., Parton, R. G., Leppla, S. H., and van der Goot, F. G. (2004). Membrane insertion of anthrax protective antigen and cytoplasmic delivery of lethal factor occur at different stages of the endocytic pathway. J. Cell Biol. 166, 645-651. doi: 10.1083/jcb.200312072 needs to be cautiously analyzed whenever we aim to better understand the role of toxins in the in vivo infectious process. The accurate role of toxins in human infections needs to be analyzed in the context of bacterial infections in different animal species. In this perspective, future efforts should concentrate in the development and use of appropriate animal models, possibly non-human primates, in which available in vitro and in vivo data can be confirmed and possibly extrapolated to the human pathologies.

\section{AUTHOR CONTRIBUTIONS}

AdV and SS wrote the manuscript. DC contributed with figures design. The manuscript content was discussed and decided by all the authors.

\section{FUNDING}

This work was supported by FEDER funds through Programa Operacional Factores de Competitividade - COMPETE and by national funds through FCT - Fundação para a Ciência e a Tecnologia (project PTDC/BIA-MIC/3463/2012 FCOMP01-0124-FEDER-028364; to AV). Research in the groups of Molecular Microbiology and Fish Immunology and Vaccinology is supported by national funds through FCT - Fundação para a Ciência e a Tecnologia/MEC - Ministério da Educação e Ciência and co-funded by FEDER within the partnership agreement PT2020 related with the research unit number 4293. The Group of Molecular Microbiology also receives support from a Research Grant 2014 by the European Society of Clinical Microbiology and Infectious Diseases (ESCMID) (to SS) and the PT2020 research project Infect-ERA/0001/2013 PROANTILIS. AdV received the FCT fellowship SFRH/BPD/95777/2013 by national funds through FCT - Fundação para a Ciência e a Tecnologia/MEC - Ministério da Educação e Ciência and cofunded by QREN and POPH (Programa Operacional Potencial Humano). SS is supported by FCT-Investigator program.

\section{ACKNOWLEDGMENTS}

We apologize to authors whose relevant work could not be cited owing to space limitations. We thank Nuno MS dos Santos (IBMC/I3S, Porto, Portugal) for critical reading of the manuscript and Jorge Pedrosa (ICVS/Universidade do Minho, Braga, Portugal) for reviewing the content concerning mycolactone.
Abrami, L., Liu, S., Cosson, P., Leppla, S. H., and van der Goot, F. G. (2003). Anthrax toxin triggers endocytosis of its receptor via a lipid raft-mediated clathrin-dependent process. J. Cell. Biol. 160, 321-328. doi: $10.1083 /$ jcb. 200211018

Adusumilli, S., Mve-Obiang, A., Sparer, T., Meyers, W., Hayman, J., and Small, P. L. (2005). Mycobacterium ulcerans toxic macrolide, mycolactone modulates the 
host immune response and cellular location of M. ulcerans in vitro and in vivo. Cell. Microbiol. 7, 1295-1304. doi: 10.1111/j.1462-5822.2005.00557.x

Agrawal, A., Lingappa, J., Leppla, S. H., Agrawal, S., Jabbar, A., Quinn, C., et al. (2003). Impairment of dendritic cells and adaptive immunity by anthrax lethal toxin. Nature 424, 329-334. doi: 10.1038/nature01794

Ahmad, J. N., Cerny, O., Linhartova, I., Masin, J., Osicka, R., and Sebo, P. (2015). cAMP signaling of Bordetella adenylate cyclase toxin through the SHP-1 phosphatase activates the BimEL-Bax pro-apoptotic cascade in phagocytes. Cell Microbiol. doi: 10.1111/cmi.12519 [Epub ahead of print].

Alileche, A., Serfass, E. R., Muehlbauer, S. M., Porcelli, S. A., and Brojatsch, J. (2005). Anthrax lethal toxin-mediated killing of human and murine dendritic cells impairs the adaptive immune response. PLoS Pathog 1:e19. doi: 10.1371/journal.ppat.0010019

Alonzo, F. III, Benson, M. A., Chen, J., Novick, R. P., Shopsin, B., and Torres, V. J. (2012). Staphylococcus aureus leucocidin ED contributes to systemic infection by targeting neutrophils and promoting bacterial growth in vivo. Mol. Microbiol. 83, 423-435. doi: 10.1111/j.1365-2958.2011.07942.x

Alonzo, F. III, Kozhaya, L., Rawlings, S. A., Reyes-Robles, T., DuMont, A. L., Myszka, D. G., et al. (2013). CCR5 is a receptor for Staphylococcus aureus leukotoxin ED. Nature 493, 51-55. doi: 10.1038/nature11724

Andreasen, C., and Carbonetti, N. H. (2008). Pertussis toxin inhibits early chemokine production to delay neutrophil recruitment in response to Bordetella pertussis respiratory tract infection in mice. Infect. Immun. 76, 5139-5148. doi: 10.1128/IAI.00895-08

Andreasen, C., and Carbonetti, N. H. (2009). Role of neutrophils in response to Bordetella pertussis infection in mice. Infect. Immun. 77, 1182-1188. doi: 10.1128/IAI.01150-08

Andreasen, C., Powell, D. A., and Carbonetti, N. H. (2009). Pertussis toxin stimulates IL-17 production in response to Bordetella pertussis infection in mice. PLoS ONE 4:e7079. doi: 10.1371/journal.pone.0007079

Appelberg, R. (2007). Neutrophils and intracellular pathogens: beyond phagocytosis and killing. Trends Microbiol. 15, 87-92. doi: 10.1016/j.tim.2006.11.009

Arango Duque, G., and Descoteaux, A. (2014). Macrophage cytokines: involvement in immunity and infectious diseases. Front. Immunol. 5:491. doi: 10.3389/fimmu.2014.00491

Baker, H. M., Basu, I., Chung, M. C., Caradoc-Davies, T., Fraser, J. D., and Baker, E. N. (2007). Crystal structures of the staphylococcal toxin SSL5 in complex with sialyl Lewis X reveal a conserved binding site that shares common features with viral and bacterial sialic acid binding proteins. J. Mol. Biol. 374, 1298-1308. doi: 10.1016/j.jmb.2007.09.091

Baldari, C. T., Tonello, F., Paccani, S. R., and Montecucco, C. (2006). Anthrax toxins: a paradigm of bacterial immune suppression. Trends Immunol. 27, 434-440. doi: 10.1016/j.it.2006.07.002

Barnes, A. C., dos Santos, N. M., and Ellis, A. E. (2005). Update on bacterial vaccines: Photobacterium damselae subsp. piscicida. Dev. Biol. (Basel) 121, 75-84.

Barson, H. V., Mollenkopf, H., Kaufmann, S. H., and Rijpkema, S. (2008). Anthrax lethal toxin suppresses chemokine production in human neutrophil NB-4 cells. Biochem. Biophys. Res. Commun. 374, 288-293. doi: 10.1016/j.bbrc.2008.07.018

Barth, H., Fischer, S., Moglich, A., and Fortsch, C. (2015). Clostridial C3 toxins target monocytes/macrophages and modulate their functions. Front. Immunol. 6:339. doi: 10.3389/fimmu.2015.00339

Baruch, K., Gur-Arie, L., Nadler, C., Koby, S., Yerushalmi, G., Ben-Neriah, Y., et al. (2011). Metalloprotease type III effectors that specifically cleave JNK and NF-kappaB. EMBO J. 30, 221-231. doi: 10.1038/emboj.2010.297

Bassinet, L., Gueirard, P., Maitre, B., Housset, B., Gounon, P., and Guiso, N. (2000). Role of adhesins and toxins in invasion of human tracheal epithelial cells by Bordetella pertussis. Infect. Immun. 68, 1934-1941. doi: 10.1128/IAI.68.4.19341941.2000

Becker, R. E., Berube, B. J., Sampedro, G. R., DeDent, A. C., and Bubeck Wardenburg, J. (2014). Tissue-specific patterning of host innate immune responses by Staphylococcus aureus alpha-toxin. J. Innate Immun. 6, 619-631. doi: $10.1159 / 000360006$

Berends, E. T., Horswill, A. R., Haste, N. M., Monestier, M., Nizet, V., and von Kockritz-Blickwede, M. (2010). Nuclease expression by Staphylococcus aureus facilitates escape from neutrophil extracellular traps. J. Innate Immun. 2, 576-586. doi: 10.1159/000319909
Bergman, N. H., Passalacqua, K. D., Gaspard, R., Shetron-Rama, L. M., Quackenbush, J., and Hanna, P. C. (2005). Murine macrophage transcriptional responses to Bacillus anthracis infection and intoxication. Infect. Immun. 73, 1069-1080. doi: 10.1128/IAI.73.2.1069-1080.2005

Berube, B. J., and Bubeck Wardenburg, J. (2013). Staphylococcus aureus alphatoxin: nearly a century of intrigue. Toxins (Basel) 5, 1140-1166. doi: 10.3390/toxins5061140

Bestebroer, J., Aerts, P. C., Rooijakkers, S. H., Pandey, M. K., Kohl, J., van Strijp, J. A., et al. (2010). Functional basis for complement evasion by staphylococcal superantigen-like 7. Cell Microbiol. 12, 1506-1516. doi: 10.1111/j.1462-5822.2010.01486.x

Bestebroer, J., Poppelier, M. J., Ulfman, L. H., Lenting, P. J., Denis, C. V., van Kessel, K. P., et al. (2007). Staphylococcal superantigen-like 5 binds PSGL-1 and inhibits P-selectin-mediated neutrophil rolling. Blood 109, 2936-2943.

Bestebroer, J., van Kessel, K. P., Azouagh, H., Walenkamp, A. M., Boer, I. G., Romijn, R. A., et al. (2009). Staphylococcal SSL5 inhibits leukocyte activation by chemokines and anaphylatoxins. Blood 113, 328-337. doi: 10.1182/blood2008-04-153882

Bischof, T. S., Hahn, B. L., and Sohnle, P. G. (2007). Characteristics of spore germination in a mouse model of cutaneous anthrax. J. Infect. Dis. 195, 888-894. doi: $10.1086 / 511824$

Boyd, A. P., Ross, P. J., Conroy, H., Mahon, N., Lavelle, E. C., and Mills, K. H. (2005). Bordetella pertussis adenylate cyclase toxin modulates innate and adaptive immune responses: distinct roles for acylation and enzymatic activity in immunomodulation and cell death. J. Immunol. 175, 730-738. doi: 10.4049/jimmunol.175.2.730

Boyden, E. D., and Dietrich, W. F. (2006). Nalp1b controls mouse macrophage susceptibility to anthrax lethal toxin. Nat. Genet. 38, 240-244. doi: 10.1038/ng1724

Bradley, K. A., Mogridge, J., Mourez, M., Collier, R. J., and Young, J. A. (2001). Identification of the cellular receptor for anthrax toxin. Nature 414, 225-229. doi: $10.1038 / \mathrm{n} 35101999$

Brittingham, K. C., Ruthel, G., Panchal, R. G., Fuller, C. L., Ribot, W. J., Hoover, T. A., et al. (2005). Dendritic cells endocytose Bacillus anthracis spores: implications for anthrax pathogenesis. J. Immunol. 174, 5545-5552. doi: 10.4049/jimmunol.174.9.5545

Bubeck Wardenburg, J., Patel, R. J., and Schneewind, O. (2007). Surface proteins and exotoxins are required for the pathogenesis of Staphylococcus aureus pneumonia. Infect. Immun. 75, 1040-1044. doi: 10.1128/IAI.01313-06

Bubeck Wardenburg, J., and Schneewind, O. (2008). Vaccine protection against Staphylococcus aureus pneumonia. J. Exp. Med. 205, 287-294. doi: 10.1084/jem.20072208

Bumba, L., Masin, J., Fiser, R., and Sebo, P. (2010). Bordetella adenylate cyclase toxin mobilizes its beta2 integrin receptor into lipid rafts to accomplish translocation across target cell membrane in two steps. PLoS Pathog. 6:e1000901. doi: 10.1371/journal.ppat.1000901

Carbonetti, N. H. (2007). Immunomodulation in the pathogenesis of Bordetella pertussis infection and disease. Curr. Opin. Pharmacol. 7, 272-278. doi: 10.1016/j.coph.2006.12.004

Carbonetti, N. H. (2010). Pertussis toxin and adenylate cyclase toxin: key virulence factors of Bordetella pertussis and cell biology tools. Future Microbiol. 5, 455469. doi: $10.2217 /$ fmb.09.133

Carbonetti, N. H., Artamonova, G. V., Andreasen, C., and Bushar, N. (2005). Pertussis toxin and adenylate cyclase toxin provide a one-two punch for establishment of Bordetella pertussis infection of the respiratory tract. Infect. Immun. 73, 2698-2703. doi: 10.1128/IAI.73.5.2698-2703.2005

Carbonetti, N. H., Artamonova, G. V., Mays, R. M., and Worthington, Z. E. (2003). Pertussis toxin plays an early role in respiratory tract colonization by Bordetella pertussis. Infect. Immun. 71, 6358-6366. doi: 10.1128/IAI.71.11.6358-63 66.2003

Carbonetti, N. H., Artamonova, G. V., Van Rooijen, N., and Ayala, V. I. (2007). Pertussis toxin targets airway macrophages to promote Bordetella pertussis infection of the respiratory tract. Infect. Immun. 75, 1713-1720. doi: 10.1128/IAI.01578-06

Cerny, O., Kamanova, J., Masin, J., Bibova, I., Skopova, K., and Sebo, P. (2015). Bordetella pertussis adenylate cyclase toxin blocks induction of bactericidal nitric oxide in macrophages through cAMP-dependent activation of the SHP-1 phosphatase. J. Immunol. 194, 4901-4913. doi: 10.4049/jimmunol.1402941 
Chatterjee, S. S., Joo, H. S., Duong, A. C., Dieringer, T. D., Tan, V. Y., Song, Y., et al. (2013). Essential Staphylococcus aureus toxin export system. Nat. Med. 19, 364-367. doi: 10.1038/nm.3047

Chavakis, T., Hussain, M., Kanse, S. M., Peters, G., Bretzel, R. G., Flock, J. I., et al. (2002). Staphylococcus aureus extracellular adherence protein serves as antiinflammatory factor by inhibiting the recruitment of host leukocytes. Nat. Med. 8, 687-693. doi: $10.1038 / \mathrm{nm} 728$

Chavarria-Smith, J., and Vance, R. E. (2013). Direct proteolytic cleavage of NLRP1B is necessary and sufficient for inflammasome activation by anthrax lethal factor. PLoS Pathog. 9:e1003452. doi: 10.1371/journal.ppat.1003452

Chavarria-Smith, J., and Vance, R. E. (2015). The NLRP1 inflammasomes. Immunol. Rev. 265, 22-34. doi: 10.1111/imr.12283

Cheung, G. Y., Joo, H. S., Chatterjee, S. S., and Otto, M. (2014a). Phenol-soluble modulins-critical determinants of staphylococcal virulence. FEMS Microbiol. Rev. 38, 698-719. doi: 10.1111/1574-6976.12057

Cheung, G. Y., Kretschmer, D., Duong, A. C., Yeh, A. J., Ho, T. V., Chen, Y., et al. (2014b). Production of an attenuated phenol-soluble modulin variant unique to the MRSA clonal complex 30 increases severity of bloodstream infection. PLoS Pathog. 10:e1004298. doi: 10.1371/journal.ppat.1004298

Cocklin, S., Jost, M., Robertson, N. M., Weeks, S. D., Weber, H. W., Young, E., et al. (2006). Real-time monitoring of the membrane-binding and insertion properties of the cholesterol-dependent cytolysin anthrolysin $\mathrm{O}$ from Bacillus anthracis. J. Mol. Recogn. 19, 354-362. doi: 10.1002/jmr.784

Coggeshall, K. M., Lupu, F., Ballard, J., Metcalf, J. P., James, J. A., Farris, D., et al. (2013). The sepsis model: an emerging hypothesis for the lethality of inhalation anthrax. J. Cell Mol. Med. 17, 914-920. doi: 10.1111/jcmm.12075

Collier, R. J. (2009). Membrane translocation by anthrax toxin. Mol. Aspects Med. 30, 413-422. doi: 10.1016/j.mam.2009.06.003

Confer, D. L., and Eaton, J. W. (1982). Phagocyte impotence caused by an invasive bacterial adenylate cyclase. Science 217, 948-950. doi: 10.1126/science.6287574

Connelly, C. E., Sun, Y., and Carbonetti, N. H. (2012). Pertussis toxin exacerbates and prolongs airway inflammatory responses during Bordetella pertussis infection. Infect. Immun. 80, 4317-4332. doi: 10.1128/IAI.00808-12

Corre, J. P., Piris-Gimenez, A., Moya-Nilges, M., Jouvion, G., Fouet, A., Glomski, I. J., et al. (2013). In vivo germination of Bacillus anthracis spores during murine cutaneous infection. J. Infect. Dis. 207, 450-457. doi: 10.1093/infdis/jis686

Costa-Ramos, C., Vale, A., Ludovico, P., Dos Santos, N. M., and Silva, M. T. (2011). The bacterial exotoxin AIP56 induces fish macrophage and neutrophil apoptosis using mechanisms of the extrinsic and intrinsic pathways. Fish Shellfish Immunol. 30, 173-181. doi: 10.1016/j.fsi.2010.10.007

Coutanceau, E., Marsollier, L., Brosch, R., Perret, E., Goossens, P., Tanguy, M., et al. (2005). Modulation of the host immune response by a transient intracellular stage of Mycobacterium ulcerans: the contribution of endogenous mycolactone toxin. Cell. Microbiol. 7, 1187-1196. doi: 10.1111/j.1462-5822.2005.00546.x

Cowan, G. J., Atkins, H. S., Johnson, L. K., Titball, R. W., and Mitchell, T. J. (2007). Immunisation with anthrolysin $\mathrm{O}$ or a genetic toxoid protects against challenge with the toxin but not against Bacillus anthracis. Vaccine 25, 7197-7205. doi: 10.1016/j.vaccine.2007.07.040

Crawford, M. A., Aylott, C. V., Bourdeau, R. W., and Bokoch, G. M. (2006). Bacillus anthracis toxins inhibit human neutrophil NADPH oxidase activity. J. Immunol. 176, 7557-7565. doi: 10.4049/jimmunol.176.12.7557

de Haas, C. J., Veldkamp, K. E., Peschel, A., Weerkamp, F., Van Wamel, W. J., Heezius, E. C., et al. (2004). Chemotaxis inhibitory protein of Staphylococcus aureus, a bacterial antiinflammatory agent. J. Exp. Med. 199, 687-695. doi: 10.1084/jem.20031636

de Haas, C. J., Weeterings, C., Vughs, M. M., de Groot, P. G., Van Strijp, J. A., and Lisman, T. (2009). Staphylococcal superantigen-like 5 activates platelets and supports platelet adhesion under flow conditions, which involves glycoprotein Ibalpha and alpha IIb beta 3. J. Thromb. Haemost. 7, 1867-1874. doi: 10.1111/j.1538-7836.2009.03564.x

Degnan, P. H., Yu, Y., Sisneros, N., Wing, R. A., and Moran, N. A. (2009). Hamiltonella defensa, genome evolution of protective bacterial endosymbiont from pathogenic ancestors. Proc. Natl. Acad. Sci. U.S.A. 106, 9063-9068. doi: 10.1073/pnas.0900194106

do Vale, A., Costa-Ramos, C., Silva, A., Silva, D. S., Gartner, F., dos Santos, N. M., et al. (2007). Systemic macrophage and neutrophil destruction by secondary necrosis induced by a bacterial exotoxin in a Gram-negative septicaemia. Cell. Microbiol. 9, 988-1003. doi: 10.1111/j.1462-5822.2006.00846.x do Vale, A., Marques, F., and Silva, M. T. (2003). Apoptosis of sea bass (Dicentrarchus labrax L.) neutrophils and macrophages induced by experimental infection with Photobacterium damselae subsp. piscicida. Fish Shellfish Immunol. 15, 129-144. doi: 10.1016/S1050-4648(02)00144-4

do Vale, A., Silva, M. T., dos Santos, N. M., Nascimento, D. S., Reis-Rodrigues, P., Costa-Ramos, C., et al. (2005). AIP56, a novel plasmid-encoded virulence factor of Photobacterium damselae subsp. piscicida with apoptogenic activity against sea bass macrophages and neutrophils. Mol. Microbiol. 58, 1025-1038. doi: 10.1111/j.1365-2958.2005.04893.x

Duesbery, N. S., Webb, C. P., Leppla, S. H., Gordon, V. M., Klimpel, K. R., Copeland, T. D., et al. (1998). Proteolytic inactivation of MAP-kinase-kinase by anthrax lethal factor. Science 280, 734-737. doi: 10.1126/science.280.53 64.734

DuMont, A. L., Yoong, P., Day, C. J., Alonzo, F. III, McDonald, W. H., Jennings, M. P., et al. (2013a). Staphylococcus aureus LukAB cytotoxin kills human neutrophils by targeting the CD11b subunit of the integrin Mac-1. Proc. Natl. Acad. Sci. U.S.A. 110, 10794-10799. doi: 10.1073/pnas. 1305121110

DuMont, A. L., Yoong, P., Surewaard, B. G., Benson, M. A., Nijland, R., van Strijp, J. A., et al. (2013b). Staphylococcus aureus elaborates leukocidin AB to mediate escape from within human neutrophils. Infect. Immun. 81, 1830-1841. doi: 10.1128/IAI.00095-13

During, R. L., Gibson, B. G., Li, W., Bishai, E. A., Sidhu, G. S., Landry, J., et al. (2007). Anthrax lethal toxin paralyzes actin-based motility by blocking Hsp27 phosphorylation. EMBO J. 26, 2240-2250. doi: 10.1038/sj.emboj.7601687

During, R. L., Li, W., Hao, B., Koenig, J. M., Stephens, D. S., Quinn, C. P., et al. (2005). Anthrax lethal toxin paralyzes neutrophil actin-based motility. J. Infect. Dis. 192, 837-845. doi: 10.1086/432516

Eby, J. C., Gray, M. C., and Hewlett, E. L. (2014). Cyclic AMP-mediated suppression of neutrophil extracellular trap formation and apoptosis by the Bordetella pertussis adenylate cyclase toxin. Infect. Immun. 82, 5256-5269. doi: 10.1128/IAI.02487-14

Eby, J. C., Gray, M. C., Mangan, A. R., Donato, G. M., and Hewlett, E. L. (2012). Role of CD11b/CD18 in the process of intoxication by the adenylate cyclase toxin of Bordetella pertussis. Infect. Immun. 80, 850-859. doi: 10.1128/IAI.05979-11

Eby, J. C., Gray, M. C., Warfel, J. M., Paddock, C. D., Jones, T. F., Day, S. R., et al. (2013). Quantification of the adenylate cyclase toxin of Bordetella pertussis in vitro and during respiratory infection. Infect. Immun. 81, 1390-1398. doi: 10.1128/IAI.00110-13

Eby, J. C., Hoffman, C. L., Gonyar, L. A., and Hewlett, E. L. (2015). Review of the neutrophil response to Bordetella pertussis infection. Pathog. Dis. 73, pii:ftv081. doi: 10.1093/femspd/ftv081

Erwin, J. L., DaSilva, L. M., Bavari, S., Little, S. F., Friedlander, A. M., and Chanh, T. C. (2001). Macrophage-derived cell lines do not express proinflammatory cytokines after exposure to Bacillus anthracis lethal toxin. Infect. Immun. 69, 1175-1177. doi: 10.1128/IAI.69.2.1175-1177.2001

Firoved, A. M., Miller, G. F., Moayeri, M., Kakkar, R., Shen, Y., Wiggins, J. F., et al. (2005). Bacillus anthracis edema toxin causes extensive tissue lesions and rapid lethality in mice. Am. J. Pathol. 167, 1309-1320. doi: 10.1016/S00029440(10)61218-7

Fiser, R., Masin, J., Basler, M., Krusek, J., Spulakova, V., Konopasek, I., et al. (2007). Third activity of Bordetella adenylate cyclase (AC) toxin-hemolysin. Membrane translocation of AC domain polypeptide promotes calcium influx into CD11b+ monocytes independently of the catalytic and hemolytic activities. J. Biol. Chem. 282, 2808-2820. doi: 10.1074/jbc.M609979200

Fiser, R., Masin, J., Bumba, L., Pospisilova, E., Fayolle, C., Basler, M., et al. (2012). Calcium influx rescues adenylate cyclase-hemolysin from rapid cell membrane removal and enables phagocyte permeabilization by toxin pores. PLoS Pathog. 8:e1002580. doi: 10.1371/journal.ppat.1002580

Flannagan, R. S., Cosio, G., and Grinstein, S. (2009). Antimicrobial mechanisms of phagocytes and bacterial evasion strategies. Nat. Rev. Microbiol. 7, 355-366. doi: $10.1038 /$ nrmicro 2128

Friedman, R. L., Fiederlein, R. L., Glasser, L., and Galgiani, J. N. (1987). Bordetella pertussis adenylate cyclase: effects of affinity-purified adenylate cyclase on human polymorphonuclear leukocyte functions. Infect. Immun. 55, 135-140.

Fu, H., Karlsson, J., Bylund, J., Movitz, C., Karlsson, A., and Dahlgren, C. (2006). Ligand recognition and activation of formyl peptide receptors in neutrophils. J. Leukoc. Biol. 79, 247-256. doi: 10.1189/jlb.0905498 
Gama, J. B., Ohlmeier, S., Martins, T. G., Fraga, A. G., Sampaio-Marques, B., Carvalho, M. A., et al. (2014). Proteomic analysis of the action of the Mycobacterium ulcerans toxin mycolactone: targeting host cells cytoskeleton and collagen. PLoS Negl. Trop. Dis. 8:e3066. doi: 10.1371/journal.pntd.0003066

Geiger, T., Francois, P., Liebeke, M., Fraunholz, M., Goerke, C., Krismer, B., et al. (2012). The stringent response of Staphylococcus aureus and its impact on survival after phagocytosis through the induction of intracellular PSMs expression. PLoS Pathog. 8:e1003016. doi: 10.1371/journal.ppat.1003016

George, K. M., Barker, L. P., Welty, D. M., and Small, P. L. (1998). Partial purification and characterization of biological effects of a lipid toxin produced by Mycobacterium ulcerans. Infect. Immun. 66, 587-593.

George, K. M., Chatterjee, D., Gunawardana, G., Welty, D., Hayman, J., Lee, R., et al. (1999). Mycolactone: a polyketide toxin from Mycobacterium ulcerans required for virulence. Science 283, 854-857. doi: 10.1126/science.283.5403.854

George, K. M., Pascopella, L., Welty, D. M., and Small, P. L. (2000). A Mycobacterium ulcerans toxin, mycolactone, causes apoptosis in guinea pig ulcers and tissue culture cells. Infect. Immun. 68, 877-883. doi: 10.1128/IAI.68.2.877-883.2000

Goodwin, M. S., and Weiss, A. A. (1990). Adenylate cyclase toxin is critical for colonization and pertussis toxin is critical for lethal infection by Bordetella pertussis in infant mice. Infect. Immun. 58, 3445-3447.

Gordon, V. M., Leppla, S. H., and Hewlett, E. L. (1988). Inhibitors of receptormediated endocytosis block the entry of Bacillus anthracis adenylate cyclase toxin but not that of Bordetella pertussis adenylate cyclase toxin. Infect. Immun. $56,1066-1069$

Grosz, M., Kolter, J., Paprotka, K., Winkler, A. C., Schafer, D., Chatterjee, S. S., et al. (2014). Cytoplasmic replication of Staphylococcus aureus upon phagosomal escape triggered by phenol-soluble modulin alpha. Cell. Microbiol. 16, 451-465. doi: $10.1111 / \mathrm{cmi} .12233$

Gueirard, P., Druilhe, A., Pretolani, M., and Guiso, N. (1998). Role of adenylate cyclase-hemolysin in alveolar macrophage apoptosis during Bordetella pertussis infection in vivo. Infect. Immun. 66, 1718-1725.

Guenin-Mace, L., Carrette, F., Asperti-Boursin, F., Le Bon, A., Caleechurn, L., Di Bartolo, V., et al. (2011). Mycolactone impairs T cell homing by suppressing microRNA control of L-selectin expression. Proc. Natl. Acad. Sci. U.S.A. 108, 12833-12838. doi: 10.1073/pnas. 1016496108

Guenin-Mace, L., Veyron-Churlet, R., Thoulouze, M. I., Romet-Lemonne, G., Hong, H., Leadlay, P. F., et al. (2013). Mycolactone activation of WiskottAldrich syndrome proteins underpins Buruli ulcer formation. J. Clin. Invest. 123, 1501-1512. doi: 10.1172/JCI66576

Guermonprez, P., Khelef, N., Blouin, E., Rieu, P., Ricciardi-Castagnoli, P., Guiso, N., et al. (2001). The adenylate cyclase toxin of Bordetella pertussis binds to target cells via the alpha(M)beta(2) integrin (CD11b/CD18). J. Exp. Med. 193, 1035-1044. doi: 10.1084/jem.193.9.1035

Guidi-Rontani, C., Weber-Levy, M., Labruyere, E., and Mock, M. (1999). Germination of Bacillus anthracis spores within alveolar macrophages. Mol. Microbiol. 31, 9-17. doi: 10.1046/j.1365-2958.1999.01137.x

Haas, P. J., de Haas, C. J., Kleibeuker, W., Poppelier, M. J., van Kessel, K. P., Kruijtzer, J. A., et al. (2004). N-terminal residues of the chemotaxis inhibitory protein of Staphylococcus aureus are essential for blocking formylated peptide receptor but not C5a receptor. J. Immunol. 173, 5704-5711. doi: 10.4049/jimmunol.173.9.5704

Haas, P. J., de Haas, C. J., Poppelier, M. J., van Kessel, K. P., van Strijp, J. A., Dijkstra, K., et al. (2005). The structure of the C5a receptor-blocking domain of chemotaxis inhibitory protein of Staphylococcus aureus is related to a group of immune evasive molecules. J. Mol. Biol. 353, 859-872. doi: 10.1016/j.jmb.2005.09.014

Hall, B., and Simmonds, R. (2014). Pleiotropic molecular effects of the Mycobacterium ulcerans virulence factor mycolactone underlying the cell death and immunosuppression seen in Buruli ulcer. Biochem. Soc. Trans. 42, 177-183. doi: 10.1042/BST20130133

Hall, B. S., Hill, K., McKenna, M., Ogbechi, J., High, S., Willis, A. E., et al. (2014). The pathogenic mechanism of the Mycobacterium ulcerans virulence factor, mycolactone, depends on blockade of protein translocation into the ER. PLoS Pathog. 10:e1004061. doi: 10.1371/journal.ppat.1004061

Hanna, P. C., and Ireland, J. A. (1999). Understanding Bacillus anthracis pathogenesis. Trends Microbiol. 7, 180-182. doi: 10.1016/S0966842X(99)01507-3
Harvill, E. T., Cotter, P. A., Yuk, M. H., and Miller, J. F. (1999). Probing the function of Bordetella bronchiseptica adenylate cyclase toxin by manipulating host immunity. Infect. Immun. 67, 1493-1500.

Haupt, K., Reuter, M., van den Elsen, J., Burman, J., Halbich, S., Richter, J., et al. (2008). The Staphylococcus aureus protein Sbi acts as a complement inhibitor and forms a tripartite complex with host complement Factor $\mathrm{H}$ and C3b. PLoS Pathog. 4:e1000250. doi: 10.1371/journal.ppat.1000250

Hawke, J. P., Plakas, S. M., Minton, R. V., McPhearson, R. M., Snider, T. G., and Guarino, A. M. (1987). Fish pasteurellosis of cultured striped bass (Morone saxatilis) in coastal Alabama. Aquaculture 65, 193-204. doi: 10.1016/00448486(87)90231-6

He, Y. X., Hewlett, E., Temeles, D., and Quesenberry, P. (1988). Inhibition of interleukin 3 and colony-stimulating factor 1-stimulated marrow cell proliferation by pertussis toxin. Blood 71, 1187-1195.

Heffernan, B. J., Thomason, B., Herring-Palmer, A., and Hanna, P. (2007). Bacillus anthracis anthrolysin $\mathrm{O}$ and three phospholipases $\mathrm{C}$ are functionally redundant in a murine model of inhalation anthrax. FEMS Microbiol. Lett. 271, 98-105. doi: 10.1111/j.1574-6968.2007.00713.x

Hellmich, K. A., Levinsohn, J. L., Fattah, R., Newman, Z. L., Maier, N., Sastalla, I., et al. (2012). Anthrax lethal factor cleaves mouse nlrp1b in both toxin-sensitive and toxin-resistant macrophages. PLOS ONE 7:e49741. doi: 10.1371/journal.pone.0049741

Hickey, F. B., Brereton, C. F., and Mills, K. H. (2008). Adenylate cycalse toxin of Bordetella pertussis inhibits TLR-induced IRF-1 and IRF-8 activation and IL12 production and enhances IL-10 through MAPK activation in dendritic cells. J. Leukoc. Biol. 84, 234-243. doi: 10.1189/jlb.0208113

Higgs, R., Higgins, S. C., Ross, P. J., and Mills, K. H. (2012). Immunity to the respiratory pathogen Bordetella pertussis. Mucosal Immunol. 5, 485-500. doi: 10.1038/mi.2012.54

Hodgson, A., Wier, E. M., Fu, K., Sun, X., Yu, H., Zheng, W., et al. (2015). Metalloprotease NleC suppresses host NF-kappaB/inflammatory responses by cleaving p65 and interfering with the p65/RPS3 interaction. PLoS Pathog 11:e1004705. doi: 10.1371/journal.ppat.1004705

Hong, H., Coutanceau, E., Leclerc, M., Caleechurn, L., Leadlay, P. F., and Demangel, C. (2008). Mycolactone diffuses from Mycobacterium ulceransinfected tissues and targets mononuclear cells in peripheral blood and lymphoid organs. PLoS Negl. Trop. Dis. 2:e325. doi: 10.1371/journal.pntd.0000325

Hsu, L. C., Park, J. M., Zhang, K., Luo, J. L., Maeda, S., Kaufman, R. J., et al. (2004). The protein kinase PKR is required for macrophage apoptosis after activation of Toll-like receptor 4. Nature 428, 341-345. doi: 10.1038/nature02405

Huang, C., Jacobson, K., and Schaller, M. D. (2004). MAP kinases and cell migration. J. Cell Sci. 117, 4619-4628. doi: 10.1242/jcs.01481

Hume, D. A., and Denkins, Y. M. (1989). Activation of macrophages to express cytocidal activity correlates with inhibition of their responsiveness to macrophage colony-stimulating factor (CSF-1): involvement of a pertussis toxin-sensitive reaction. Immunol. Cell Biol. 67(Pt 4), 243-249. doi: 10.1038/icb.1989.37

Inoshima, I., Inoshima, N., Wilke, G. A., Powers, M. E., Frank, K. M., Wang, Y., et al. (2011). A Staphylococcus aureus pore-forming toxin subverts the activity of ADAM10 to cause lethal infection in mice. Nat. Med. 17, 1310-1314. doi: $10.1038 / \mathrm{nm} .2451$

Itoh, S., Hamada, E., Kamoshida, G., Takeshita, K., Oku, T., and Tsuji, T. (2010). Staphylococcal superantigen-like protein 5 inhibits matrix metalloproteinase 9 from human neutrophils. Infect. Immun. 78, 3298-3305. doi: 10.1128/IAI.00178-10

Jongerius, I., Garcia, B. L., Geisbrecht, B. V., van Strijp, J. A., and Rooijakkers, S. H. (2010a). Convertase inhibitory properties of Staphylococcal extracellular complement-binding protein. J. Biol. Chem. 285, 14973-14979. doi: 10.1074/jbc.M109.091975

Jongerius, I., Puister, M., Wu, J., Ruyken, M., van Strijp, J. A., and Rooijakkers, S. H. (2010b). Staphylococcal complement inhibitor modulates phagocyte responses by dimerization of convertases. J. Immunol. 184, 420-425. doi: 10.4049/jimmunol.0902865

Jongerius, I., Kohl, J., Pandey, M. K., Ruyken, M., van Kessel, K. P., van Strijp, J. A., et al. (2007). Staphylococcal complement evasion by various convertaseblocking molecules. J. Exp. Med. 204, 2461-2471. doi: 10.1084/jem.20070818

Kamanova, J., Kofronova, O., Masin, J., Genth, H., Vojtova, J., Linhartova, I., et al. (2008). Adenylate cyclase toxin subverts phagocyte function by RhoA 
inhibition and unproductive ruffling. J. Immunol. 181, 5587-5597. doi: 10.4049/jimmunol.181.8.5587

Kassam, A., Der, S. D., and Mogridge, J. (2005). Differentiation of human monocytic cell lines confers susceptibility to Bacillus anthracis lethal toxin. Cell Microbiol. 7, 281-292. doi: 10.1111/j.1462-5822.2004.00458.x

Katada, T., Tamura, M., and Ui, M. (1983). The A protomer of islet-activating protein, pertussis toxin, as an active peptide catalyzing ADP-ribosylation of a membrane protein. Arch. Biochem. Biophys. 224, 290-298. doi: 10.1016/00039861(83)90212-6

Kaur, M., Singh, S., and Bhatnagar, R. (2013). Anthrax vaccines: present status and future prospects. Expert Rev. Vaccines 12, 955-970. doi: 10.1586/14760584.2013.814860

Kennedy, A. D., Bubeck Wardenburg, J., Gardner, D. J., Long, D., Whitney, A. R., Braughton, K. R., et al. (2010). Targeting of alpha-hemolysin by active or passive immunization decreases severity of USA300 skin infection in a mouse model. J. Infect. Dis. 202, 1050-1058. doi: 10.1086/656043

Khelef, N., Gounon, P., and Guiso, N. (2001). Internalization of Bordetella pertussis adenylate cyclase-haemolysin into endocytic vesicles contributes to macrophage cytotoxicity. Cell Microbiol. 3, 721-730. doi: 10.1046/j.14625822.2001.00151.x

Khelef, N., and Guiso, N. (1995). Induction of macrophage apoptosis by Bordetella pertussis adenylate cyclase-hemolysin. FEMS Microbiol. Lett. 134, 27-32. doi: 10.1111/j.1574-6968.1995.tb07909.x

Khelef, N., Sakamoto, H., and Guiso, N. (1992). Both adenylate cyclase and hemolytic activities are required by Bordetella pertussis to initiate infection. Microb. Pathog. 12, 227-235. doi: 10.1016/0882-4010(92)90057-U

Khelef, N., Zychlinsky, A., and Guiso, N. (1993). Bordetella pertussis induces apoptosis in macrophages: role of adenylate cyclase-hemolysin. Infect. Immun. 61, 4064-4071.

Kirimanjeswara, G. S., Agosto, L. M., Kennett, M. J., Bjornstad, O. N., and Harvill, E. T. (2005). Pertussis toxin inhibits neutrophil recruitment to delay antibodymediated clearance of Bordetella pertussis. J. Clin. Invest. 115, 3594-3601. doi: $10.1172 /$ JCI24609

Kretschmer, D., Gleske, A. K., Rautenberg, M., Wang, R., Koberle, M., Bohn, E., et al. (2010). Human formyl peptide receptor 2 senses highly pathogenic Staphylococcus aureus. Cell Host Microbe 7, 463-473. doi: 10.1016/j.chom.2010.05.012

Kubota, S., Kimura, T., and Egusa, S. (1970). Studies of a bacterial tuberculosis of yellow-tail. I symptomology and histopathology. Gyobyo Kenkyu 4, 111-118. doi: $10.3147 /$ jsfp.4.111

Laarman, A. J., Mijnheer, G., Mootz, J. M., van Rooijen, W. J., Ruyken, M., Malone, C. L., et al. (2012). Staphylococcus aureus Staphopain A inhibits CXCR2dependent neutrophil activation and chemotaxis. EMBO J. 31, 3607-3619. doi: 10.1038/emboj.2012.212

Laarman, A. J., Ruyken, M., Malone, C. L., van Strijp, J. A., Horswill, A. R., and Rooijakkers, S. H. (2011). Staphylococcus aureus metalloprotease aureolysin cleaves complement C3 to mediate immune evasion. J. Immunol. 186, 64456453. doi: $10.4049 /$ jimmunol. 1002948

Ladant, D., and Ullmann, A. (1999). Bordatella pertussis adenylate cyclase: a toxin with multiple talents. Trends Microbiol. 7, 172-176. doi: 10.1016/S0966842X(99)01468-7

Lemichez, E., and Barbieri, J. T. (2013). General aspects and recent advances on bacterial protein toxins. Cold Spring Harb Perspect. Med. 3:a013573. doi: 10.1101/cshperspect.a013573

Leppla, S. H. (1982). Anthrax toxin edema factor: a bacterial adenylate cyclase that increases cyclic AMP concentrations of eukaryotic cells. Proc. Natl. Acad. Sci. U.S.A. 79, 3162-3166. doi: 10.1073/pnas.79.10.3162

Levinsohn, J. L., Newman, Z. L., Hellmich, K. A., Fattah, R., Getz, M. A., Liu, S., et al. (2012). Anthrax lethal factor cleavage of Nlrp1 is required for activation of the inflammasome. PLoS Pathog 8:e1002638. doi: 10.1371/journal.ppat.1002638

Liu, S., Crown, D., Miller-Randolph, S., Moayeri, M., Wang, H., Hu, H., et al. (2009). Capillary morphogenesis protein-2 is the major receptor mediating lethality of anthrax toxin in vivo. Proc. Natl. Acad. Sci. U.S.A. 106, 12424-12429. doi: 10.1073/pnas.0905409106

Liu, S., Miller-Randolph, S., Crown, D., Moayeri, M., Sastalla, I., Okugawa, S., et al. (2010). Anthrax toxin targeting of myeloid cells through the CMG2 receptor is essential for establishment of Bacillus anthracis infections in mice. Cell Host Microbe 8, 455-462. doi: 10.1016/j.chom.2010.10.004
Liu, S., Moayeri, M., and Leppla, S. H. (2014). Anthrax lethal and edema toxins in anthrax pathogenesis. Trends Microbiol. 22, 317-325. doi: 10.1016/j.tim.2014.02.012

Liu, S., Zhang, Y., Moayeri, M., Liu, J., Crown, D., Fattah, R. J., et al. (2013). Key tissue targets responsible for anthrax-toxin-induced lethality. Nature 501, 63-68. doi: 10.1038/nature 12510

Locht, C., Coutte, L., and Mielcarek, N. (2011). The ins and outs of pertussis toxin. FEBS J. 278, 4668-4682. doi: 10.1111/j.1742-4658.2011.08237.x

Magariños, B., Toranzo, A. E., and Romalde, J. L. (1996). Phenotypic and pathobiological characteristics of Pasteurella piscicida. Annu. Rev. Fish Dis. 6, 41-64. doi: 10.1016/S0959-8030(96)00004-X

Malachowa, N., Kobayashi, S. D., Freedman, B., Dorward, D. W., and DeLeo, F. R. (2013). Staphylococcus aureus leukotoxin GH promotes formation of neutrophil extracellular traps. J. Immunol. 191, 6022-6029. doi: 10.4049/jimmunol.1301821

Mangmool, S., and Kurose, H. (2011). G(i/o) protein-dependent and independent actions of Pertussis Toxin (PTX). Toxins (Basel.) 3, 884-899. doi: $10.3390 /$ toxins 3070884

Mantovani, A., Cassatella, M. A., Costantini, C., and Jaillon, S. (2011). Neutrophils in the activation and regulation of innate and adaptive immunity. Nat. Rev. Immunol. 11, 519-531. doi: 10.1038/nri3024

Marsollier, L., Aubry, J., Coutanceau, E., Andre, J. P., Small, P. L., Milon, G., et al. (2005). Colonization of the salivary glands of Naucoris cimicoides by Mycobacterium ulcerans requires host plasmatocytes and a macrolide toxin, mycolactone. Cell Microbiol. 7, 935-943. doi: 10.1111/j.1462-5822.2005.00521.x

Martin, C., Uribe, K. B., Gomez-Bilbao, G., and Ostolaza, H. (2011). Adenylate cyclase toxin promotes internalisation of integrins and raft components and decreases macrophage adhesion capacity. PLoS ONE 6:e17383. doi: 10.1371/journal.pone.0017383

Mattoo, S., and Cherry, J. D. (2005). Molecular pathogenesis, epidemiology, and clinical manifestations of respiratory infections due to Bordetella pertussis and other Bordetella subspecies. Clin. Microbiol. Rev. 18, 326-382. doi: 10.1128/CMR.18.2.326-382.2005

McCarthy, A. J., and Lindsay, J. A. (2013). Staphylococcus aureus innate immune evasion is lineage-specific: a bioinfomatics study. Infect. Genet. Evol. 19, 7-14. doi: 10.1016/j.meegid.2013.06.012

Meade, B. D., Kind, P. D., Ewell, J. B., McGrath, P. P., and Manclark, C. R. (1984). In vitro inhibition of murine macrophage migration by Bordetella pertussis lymphocytosis-promoting factor. Infect. Immun. 45, 718-725.

Melvin, J. A., Scheller, E. V., Miller, J. F., and Cotter, P. A. (2014). Bordetella pertussis pathogenesis: current and future challenges. Nat. Rev. Microbiol. 12, 274-288. doi: 10.1038/nrmicro3235

Moayeri, M., Crown, D., Newman, Z. L., Okugawa, S., Eckhaus, M., Cataisson, C., et al. (2010). Inflammasome sensor Nlrplb-dependent resistance to anthrax is mediated by caspase-1, IL-1 signaling and neutrophil recruitment. PLoS Pathog 6:e1001222. doi: 10.1371/journal.ppat.1001222

Moayeri, M., Leppla, S. H., Vrentas, C., Pomerantsev, A., and Liu, S. (2015). Anthrax pathogenesis. Annu. Rev. Microbiol. 69, 185-208.

Mork, T., and Hancock, R. E. (1993). Mechanisms of nonopsonic phagocytosis of Pseudomonas aeruginosa. Infect. Immun. 61, 3287-3293.

Morse, S. I., and Morse, J. H. (1976). Isolation and properties of the leukocytosisand lymphocytosis-promoting factor of Bordetella pertussis. J. Exp. Med. 143, 1483-1502. doi: $10.1084 /$ jem.143.6.1483

Mosser, E. M., and Rest, R. F. (2006). The Bacillus anthracis cholesteroldependent cytolysin, Anthrolysin O, kills human neutrophils, monocytes and macrophages. BMC Microbiol. 6:56.

Muehlbauer, S. M., Evering, T. H., Bonuccelli, G., Squires, R. C., Ashton, A. W., Porcelli, S. A., et al. (2007). Anthrax lethal toxin kills macrophages in a strainspecific manner by apoptosis or caspase-1-mediated necrosis. Cell Cycle 6, 758-766. doi: 10.4161/cc.6.6.3991

Newman, Z. L., Printz, M. P., Liu, S., Crown, D., Breen, L., Miller-Randolph, S., et al. (2010). Susceptibility to anthrax lethal toxin-induced rat death is controlled by a single chromosome 10 locus that includes rNlrp1. PLoS Pathog 6:e1000906. doi: 10.1371/journal.ppat.1000906

Njamkepo, E., Pinot, F., Francois, D., Guiso, N., Polla, B. S., and Bachelet, M. (2000). Adaptive responses of human monocytes infected by Bordetella pertussis: the role of adenylate cyclase hemolysin. J. Cell Physiol. 183, 91-99. doi: 10.1002/(SICI)1097-4652(200004)183:1\%3C91::AID-JCP11\%3E3.0.CO;2-S 
Noya, M., Magariños, B., Toranzo, A., and Lamas, J. (1995). Sequential pathology of experimental pasteurellosis in gilthead seabream Sparus aurata, A light- and electron-microscopic study. Dis. Aquat. Organ. 21, 177-186. doi: 10.1111/j.1365-2052.2010.02110.x

O'Brien, J., Friedlander, A., Dreier, T., Ezzell, J., and Leppla, S. (1985). Effects of anthrax toxin components on human neutrophils. Infect. Immun. 47, 306-310.

Oliveira, M. S., Fraga, A. G., Torrado, E., Castro, A. G., Pereira, J. P., Filho, A. L., et al. (2005). Infection with Mycobacterium ulcerans induces persistent inflammatory responses in mice. Infect. Immun. 73, 6299-6310. doi: 10.1128/IAI.73.10.6299-6310.2005

Otto, M. (2014). Staphylococcus aureus toxins. Curr. Opin. Microbiol. 17, 32-37. doi: 10.1016/j.mib.2013.11.004

Paccani, S. R., Dal Molin, F., Benagiano, M., Ladant, D., D'Elios, M. M., Montecucco, C., et al. (2008). Suppression of T-lymphocyte activation and chemotaxis by the adenylate cyclase toxin of Bordetella pertussis. Infect. Immun. 76, 2822-2832. doi: 10.1128/IAI.00200-08

Paccani, S. R., Finetti, F., Davi, M., Patrussi, L., D’Elios, M. M., Ladant, D., et al. (2011). The Bordetella pertussis adenylate cyclase toxin binds to T cells via LFA1 and induces its disengagement from the immune synapse. J. Exp. Med. 208, 1317-1330. doi: 10.1084/jem.20101558

Papayannopoulos, V., and Zychlinsky, A. (2009). NETs: a new strategy for using old weapons. Trends Immunol. 30, 513-521. doi: 10.1016/j.it.20 09.07.011

Park, J. M., Greten, F. R., Li, Z. W., and Karin, M. (2002). Macrophage apoptosis by anthrax lethal factor through p38 MAP kinase inhibition. Science 297, 2048-2051. doi: 10.1126/science. 1073163

Park, J. M., Greten, F. R., Wong, A., Westrick, R. J., Arthur, J. S., Otsu, K., et al. (2005). Signaling pathways and genes that inhibit pathogen-induced macrophage apoptosis-CREB and NF-kappaB as key regulators. Immunity 23, 319-329. doi: 10.1016/j.immuni.2005.08.010

Parnaik, R., Raff, M. C., and Scholes, J. (2000). Differences between the clearance of apoptotic cells by professional and non-professional phagocytes. Curr. Biol. 10, 857-860. doi: 10.1016/S0960-9822(00)00598-4

Patel, D., Wines, B. D., Langley, R. J., and Fraser, J. D. (2010). Specificity of staphylococcal superantigen-like protein 10 toward the human IgG1 Fc domain. J. Immunol. 184, 6283-6292. doi: 10.4049/jimmunol.0903311

Pearson, J. S., Riedmaier, P., Marches, O., Frankel, G., and Hartland, E. L. (2011). A type III effector protease NleC from enteropathogenic Escherichia coli targets NF-kappaB for degradation. Mol. Microbiol. 80, 219-230. doi: 10.1111/j.13652958.2011.07568.x

Pellizzari, R., Guidi-Rontani, C., Vitale, G., Mock, M., and Montecucco, C. (1999). Anthrax lethal factor cleaves MKK3 in macrophages and inhibits the LPS/IFNgamma-induced release of NO and TNFalpha. FEBS Lett. 462, 199204. doi: 10.1016/S0014-5793(99)01502-1

Pereira, L. M., Pinto, R. D., Silva, D. S., Moreira, A. R., Beitzinger, C., Oliveira, P., et al. (2014). Intracellular trafficking of AIP56, an NF-kappaB-cleaving toxin from Photobacterium damselae subsp. piscicida. Infect Immun. 82, 5270-5285. doi: 10.1128/IAI.02623-14

Peschel, A., and Otto, M. (2013). Phenol-soluble modulins and staphylococcal infection. Nat. Rev. Microbiol. 11, 667-673. doi: 10.1038/nrmicro3110

Pittman, M. (1984). The concept of pertussis as a toxin-mediated disease. Pediatr. Infect. Dis. 3, 467-486. doi: 10.1097/00006454-198409000-00019

Plaut, R. D., and Carbonetti, N. H. (2008). Retrograde transport of pertussis toxin in the mammalian cell. Cell Microbiol. 10, 1130-1139. doi: 10.1111/j.14625822.2007.01115.x

Popov, S. G., Villasmil, R., Bernardi, J., Grene, E., Cardwell, J., Wu, A., et al. (2002). Lethal toxin of Bacillus anthracis causes apoptosis of macrophages. Biochem. Biophys. Res. Commun. 293, 349-355. doi: 10.1016/S0006-291X(02)00227-9

Prat, C., Bestebroer, J., de Haas, C. J., van Strijp, J. A., and van Kessel, K. P. (2006). A new staphylococcal anti-inflammatory protein that antagonizes the formyl peptide receptor-like 1. J. Immunol. 177, 8017-8026. doi: 10.4049/jimmunol.177.11.8017

Prat, C., Haas, P. J., Bestebroer, J., de Haas, C. J., van Strijp, J. A., and van Kessel, K. P. (2009). A homolog of formyl peptide receptor-like 1 (FPRL1) inhibitor from Staphylococcus aureus (FPRL1 inhibitory protein) that inhibits FPRL1 and FPR. J. Immunol. 183, 6569-6578. doi: 10.4049/jimmunol.0801523

Rasigade, J. P., Trouillet-Assant, S., Ferry, T., Diep, B. A., Sapin, A., Lhoste, Y., et al. (2013). PSMs of hypervirulent Staphylococcus aureus act as intracellular toxins that kill infected osteoblasts. PLOS ONE 8:e63176. doi: 10.1371/journal.pone.0063176

Reis, M. I., Costa-Ramos, C., do Vale, A., and dos Santos, N. M. (2010). Molecular cloning of sea bass (Dicentrarchus labrax L.) caspase- 8 gene and its involvement in Photobacterium damselae ssp. piscicida triggered apoptosis. Fish Shellfish Immunol. 29, 58-65. doi: 10.1016/j.fsi.2010.02.016

Reis, M. I., do Vale, A., Pinto, C., Nascimento, D. S., Costa-Ramos, C., Silva, D. S., et al. (2007a). First molecular cloning and characterisation of caspase- 9 gene in fish and its involvement in a gram negative septicaemia. Mol. Immunol. 44, 1754-1764. doi: 10.1016/j.molimm.2006.07.293

Reis, M. I., Nascimento, D. S., do Vale, A., Silva, M. T., and dos Santos, N. M. (2007b). Molecular cloning and characterisation of sea bass (Dicentrarchus labrax L.) caspase-3 gene. Mol. Immunol. 44, 774-783. doi: 10.1016/j.molimm.2006.04.028

Reyes-Robles, T., Alonzo, F., III, Kozhaya, L., Lacy, D. B., Unutmaz, D., and Torres, V. J. (2013). Staphylococcus aureus leukotoxin ED targets the chemokine receptors CXCR1 and CXCR2 to kill leukocytes and promote infection. Cell Host Microbe 14, 453-459. doi: 10.1016/j.chom.2013.09.005

Ribot, W. J., Panchal, R. G., Brittingham, K. C., Ruthel, G., Kenny, T. A., Lane, D., et al. (2006). Anthrax lethal toxin impairs innate immune functions of alveolar macrophages and facilitates Bacillus anthracis survival. Infect. Immun. 74, 5029-5034. doi: 10.1128/IAI.00275-06

Romalde, J. L. (2002). Photobacterium damselae subsp. piscicida: an integrated view of a bacterial fish pathogen. Int. Microbiol. 5, 3-9. doi: 10.1007/s10123-0020051-6

Rooijakkers, S. H., Ruyken, M., Roos, A., Daha, M. R., Presanis, J. S., Sim, R. B., et al. (2005a). Immune evasion by a staphylococcal complement inhibitor that acts on C3 convertases. Nat. Immunol. 6, 920-927. doi: 10.1038/ni1235

Rooijakkers, S. H., van Wamel, W. J., Ruyken, M., van Kessel, K. P., and van Strijp, J. A. (2005b). Anti-opsonic properties of staphylokinase. Microbes Infect. 7 , 476-484. doi: 10.1016/j.micinf.2004.12.014

Rooijakkers, S. H., Wu, J., Ruyken, M., van Domselaar, R., Planken, K. L., Tzekou, A., et al. (2009). Structural and functional implications of the alternative complement pathway C3 convertase stabilized by a staphylococcal inhibitor. Nat. Immunol. 10, 721-727. doi: 10.1038/ni.1756

Saukkonen, K., Burnette, W. N., Mar, V. L., Masure, H. R., and Tuomanen, E. I. (1992). Pertussis toxin has eukaryotic-like carbohydrate recognition domains. Proc. Natl. Acad. Sci. U.S.A. 89, 118-122. doi: 10.1073/pnas.89.1.118

Scobie, H. M., Rainey, G. J., Bradley, K. A., and Young, J. A. (2003). Human capillary morphogenesis protein 2 functions as an anthrax toxin receptor. Proc. Natl. Acad. Sci. U.S.A. 100, 5170-5174. doi: 10.1073/pnas.0431 098100

Scott, S. J., Olson, C. V., and Lad, P. M. (1988). Peptide mapping studies of the pertussis toxin substrate in human neutrophils, platelets and erythrocytes. Mol. Immunol. 25, 305-311. doi: 10.1016/0161-5890(88)90022-3

Sham, H. P., Shames, S. R., Croxen, M. A., Ma, C., Chan, J. M., Khan, M. A., et al. (2011). Attaching and effacing bacterial effector NleC suppresses epithelial inflammatory responses by inhibiting NF-kappaB and p38 mitogenactivated protein kinase activation. Infect. Immun. 79, 3552-3562. doi: 10.1128/IAI.05033-11

Shannon, J. G., Ross, C. L., Koehler, T. M., and Rest, R. F. (2003). Characterization of anthrolysin $\mathrm{O}$, the Bacillus anthracis cholesterol-dependent cytolysin. Infect. Immun. 71, 3183-3189. doi: 10.1128/IAI.71.6.3183-3189.2003

Sieprawska-Lupa, M., Mydel, P., Krawczyk, K., Wojcik, K., Puklo, M., Lupa, B., et al. (2004). Degradation of human antimicrobial peptide LL-37 by Staphylococcus aureus-derived proteinases. Antimicrob. Agents Chemother. 48, 4673-4679. doi: 10.1128/AAC.48.12.4673-4679.2004

Silva, D. S., Pereira, L. M., Moreira, A. R., Ferreira-da-Silva, F., Brito, R. M., Faria, T. Q., et al. (2013). The apoptogenic toxin AIP56 is a metalloprotease A-B toxin that cleaves NF-kappab P65. PLoS Pathog 9:e1003128. doi: 10.1371/journal.ppat.1003128

Silva, M. T. (2010). When two is better than one: macrophages and neutrophils work in concert in innate immunity as complementary and cooperative partners of a myeloid phagocyte system. J. Leukoc. Biol. 87, 93-106. doi: 10.1189/jlb.0809549

Silva, M. T., and Correia-Neves, M. (2012). Neutrophils and macrophages: the main partners of phagocyte cell systems. Front. Immunol. 3:174. doi: 10.3389/fimmu.2012.00174 
Silva, M. T., do Vale, A., and dos Santos, N. M. (2008). Secondary necrosis in multicellular animals: an outcome of apoptosis with pathogenic implications. Apoptosis 13, 463-482. doi: 10.1007/s10495-008-0187-8

Silva, M. T., Portaels, F., and Pedrosa, J. (2009). Pathogenetic mechanisms of the intracellular parasite Mycobacterium ulcerans leading to Buruli ulcer. Lancet Infect. Dis. 9, 699-710. doi: 10.1016/S1473-3099(09)70234-8

Simmonds, R. E., Lali, F. V., Smallie, T., Small, P. L., and Foxwell, B. M. (2009). Mycolactone inhibits monocyte cytokine production by a posttranscriptional mechanism. J. Immunol. 182, 2194-2202. doi: 10.4049/jimmunol.0802294

Skinner, J. A., Reissinger, A., Shen, H., and Yuk, M. H. (2004). Bordetella type III secretion and adenylate cyclase toxin synergize to drive dendritic cells into a semimature state. J. Immunol. 173, 1934-1940. doi: 10.4049/jimmunol.173.3.1934

Snyder, D. S., and Small, P. L. (2003). Uptake and cellular actions of mycolactone, a virulence determinant for Mycobacterium ulcerans. Microb. Pathog. 34, 91-101. doi: 10.1016/S0882-4010(02)00210-3

Spaan, A. N., Henry, T., van Rooijen, W. J., Perret, M., Badiou, C., Aerts, P. C., et al. (2013a). The staphylococcal toxin Panton-Valentine Leukocidin targets human C5a receptors. Cell Host Microbe 13, 584-594. doi: 10.1016/j.chom.2013.04.006

Spaan, A. N., Surewaard, B. G., Nijland, R., and van Strijp, J. A. (2013b). Neutrophils versus Staphylococcus aureus: a biological tug of war. Annu. Rev. Microbiol. 67, 629-650. doi: 10.1146/annurev-micro-092412-155746

Spaan, A. N., Schiepers, A., de Haas, C. J., van Hooijdonk, D. D., Badiou, C., Contamin, H., et al. (2015). Differential interaction of the staphylococcal toxins panton-valentine leukocidin and gamma-hemolysin CB with human C5a receptors. J. Immunol. 195, 1034-1043. doi: 10.4049/jimmunol.1500604

Spaan, A. N., Vrieling, M., Wallet, P., Badiou, C., Reyes-Robles, T., Ohneck, E. A., et al. (2014). The staphylococcal toxins gamma-haemolysin AB and CB differentially target phagocytes by employing specific chemokine receptors. Nat. Commun. 5:5438. doi: 10.1038/ncomms6438

Spangrude, G. J., Sacchi, F., Hill, H. R., Van Epps, D. E., and Daynes, R. A. (1985). Inhibition of lymphocyte and neutrophil chemotaxis by pertussis toxin. J. Immunol. 135, 4135-4143.

Spensieri, F., Fedele, G., Fazio, C., Nasso, M., Stefanelli, P., Mastrantonio, P., et al. (2006). Bordetella pertussis inhibition of interleukin-12 (IL-12) p70 in human monocyte-derived dendritic cells blocks IL-12 p35 through adenylate cyclase toxin-dependent cyclic AMP induction. Infect. Immun. 74, 2831-2838. doi: 10.1128/IAI.74.5.2831-2838.2006

Stein, P. E., Boodhoo, A., Armstrong, G. D., Heerze, L. D., Cockle, S. A., Klein, M. H., et al. (1994). Structure of a pertussis toxin-sugar complex as a model for receptor binding. Nat. Struct. Biol. 1, 591-596. doi: 10.1038/nsb0994-591

Szarowicz, S. E., During, R. L., Li, W., Quinn, C. P., Tang, W. J., and Southwick, F. S. (2009). Bacillus anthracis edema toxin impairs neutrophil actin-based motility. Infect. Immun. 77, 2455-2464. doi: 10.1128/IAI.00839-08

Terra, J. K., Cote, C. K., France, B., Jenkins, A. L., Bozue, J. A., Welkos, S. L., et al. (2010). Cutting edge: resistance to Bacillus anthracis infection mediated by a lethal toxin sensitive allele of Nalp1b/Nlrp1b. J. Immunol. 184, 17-20. doi: 10.4049/jimmunol.0903114

Thammavongsa, V., Kim, H. K., Missiakas, D., and Schneewind, O. (2015). Staphylococcal manipulation of host immune responses. Nat. Rev. Microbiol. 13, 529-543. doi: 10.1038/nrmicro3521

Thammavongsa, V., Missiakas, D. M., and Schneewind, O. (2013). Staphylococcus aureus degrades neutrophil extracellular traps to promote immune cell death. Science 342, 863-866. doi: 10.1126/science.1242255

Torrado, E., Adusumilli, S., Fraga, A. G., Small, P. L., Castro, A. G., and Pedrosa, J. (2007a). Mycolactone-mediated inhibition of tumor necrosis factor production by macrophages infected with Mycobacterium ulcerans has implications for the control of infection. Infect. Immun. 75, 3979-3988. doi: 10.1128/IAI.00290-07

Torrado, E., Fraga, A. G., Castro, A. G., Stragier, P., Meyers, W. M., Portaels, F., et al. (2007b). Evidence for an intramacrophage growth phase of Mycobacterium ulcerans. Infect. Immun. 75, 977-987. doi: 10.1128/IAI.00889-06

Torrado, E., Fraga, A. G., Logarinho, E., Martins, T. G., Carmona, J. A., Gama, J. B., et al. (2010). IFN-gamma-dependent activation of macrophages during experimental infections by Mycobacterium ulcerans is impaired by the toxin mycolactone. J. Immunol. 184, 947-955. doi: 10.4049/jimmunol.0902717

Tournier, J. N., Quesnel-Hellmann, A., Mathieu, J., Montecucco, C., Tang, W. J., Mock, M., et al. (2005). Anthrax edema toxin cooperates with lethal toxin to impair cytokine secretion during infection of dendritic cells. J. Immunol. 174, 4934-4941. doi: 10.4049/jimmunol.174.8.4934

Tournier, J. N., Rossi Paccani, S., Quesnel-Hellmann, A., and Baldari, C. T. (2009). Anthrax toxins: a weapon to systematically dismantle the host immune defenses. Mol. Aspects Med. 30, 456-466. doi: 10.1016/j.mam.2009.06.002

Tung, M.-C., Tsai, S.-S., Ho, L.-F., Huang, S.-T., and Chen, S.-C. (1985). An acute septicemic infection of Pasteurella organism in pond-cultured Formosa snakehead fish (Channa maculata Lacepeda) in Taiwan. Fish Pathol. 20, 143-148. doi: $10.3147 /$ jsfp. 20.143

Vitale, G., Bernardi, L., Napolitani, G., Mock, M., and Montecucco, C. (2000). Susceptibility of mitogen-activated protein kinase kinase family members to proteolysis by anthrax lethal factor. Biochem. J. 352(Pt 3), 739-745. doi: 10.1042/bj3520739

Walenkamp, A. M., Boer, I. G., Bestebroer, J., Rozeveld, D., Timmer-Bosscha, H., Hemrika, W., et al. (2009). Staphylococcal superantigen-like 10 inhibits CXCL12-induced human tumor cell migration. Neoplasia 11, 333-344. doi: 10.1593/neo.81508

Walsh, D. S., Meyers, W. M., Portaels, F., Lane, J. E., Mongkolsirichaikul, D., Hussem, K., et al. (2005). High rates of apoptosis in human Mycobacterium ulcerans culture-positive buruli ulcer skin lesions. Am. J. Trop. Med. Hyg. 73, 410-415.

Wang, R., Braughton, K. R., Kretschmer, D., Bach, T. H., Queck, S. Y., Li, M., et al. (2007). Identification of novel cytolytic peptides as key virulence determinants for community-associated MRSA. Nat. Med. 13, 1510-1514. doi: $10.1038 / \mathrm{nm} 1656$

Weingart, C. L., and Weiss, A. A. (2000). Bordetella pertussis virulence factors affect phagocytosis by human neutrophils. Infect. Immun. 68, 1735-1739. doi: 10.1128/IAI.68.3.1735-1739.2000

Wilke, G. A., and Bubeck Wardenburg, J. (2010). Role of a disintegrin and metalloprotease 10 in Staphylococcus aureus alpha-hemolysin-mediated cellular injury. Proc. Natl. Acad. Sci. U.S.A. 107, 13473-13478. doi: 10.1073/pnas.1001815107

Witvliet, M. H., Burns, D. L., Brennan, M. J., Poolman, J. T., and Manclark, C. R. (1989). Binding of pertussis toxin to eucaryotic cells and glycoproteins. Infect. Immun. 57, 3324-3330.

Wood, W., Turmaine, M., Weber, R., Camp, V., Maki, R. A., McKercher, S. R., et al. (2000). Mesenchymal cells engulf and clear apoptotic footplate cells in macrophageless PU.1 null mouse embryos. Development 127, 5245-5252.

Wright, G. G., and Mandell, G. L. (1986). Anthrax toxin blocks priming of neutrophils by lipopolysaccharide and by muramyl dipeptide. J. Exp. Med. 164, 1700-1709. doi: 10.1084/jem.164.5.1700

Wynn, T. A., Chawla, A., and Pollard, J. W. (2013). Macrophage biology in development, homeostasis and disease. Nature 496, 445-455. doi: 10.1038 /nature 12034

Yen, H., Ooka, T., Iguchi, A., Hayashi, T., Sugimoto, N., and Tobe, T. (2010). NleC, a type III secretion protease, compromises NF-kappaB activation by targeting p65/RelA. PLoS Pathog 6:e1001231. doi: 10.1371/journal.ppat.1001231

Yokoyama, R., Itoh, S., Kamoshida, G., Takii, T., Fujii, S., Tsuji, T., et al. (2012). Staphylococcal superantigen-like protein 3 binds to the Tolllike receptor 2 extracellular domain and inhibits cytokine production induced by Staphylococcus aureus, cell wall component, or lipopeptides in murine macrophages. Infect. Immun. 80, 2816-2825. doi: 10.1128/IAI.0 0399-12

Young, J. A., and Collier, R. J. (2007). Anthrax toxin: receptor binding, internalization, pore formation, and translocation. Annu. Rev. Biochem. 76, 243-265. doi: 10.1146/annurev.biochem.75.103004.142728

Conflict of Interest Statement: The authors declare that the research was conducted in the absence of any commercial or financial relationships that could be construed as a potential conflict of interest.

Copyright (c) 2016 do Vale, Cabanes and Sousa. This is an open-access article distributed under the terms of the Creative Commons Attribution License (CC BY). The use, distribution or reproduction in other forums is permitted, provided the original author(s) or licensor are credited and that the original publication in this journal is cited, in accordance with accepted academic practice. No use, distribution or reproduction is permitted which does not comply with these terms. 